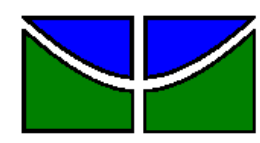

Universidade de Brasília

Faculdade de Economia, Administração, Contabilidade e Ciências da Informação e Documentação

RAFAEL MARQUES NAKAMURA

\title{
O EFEITO LEAD-LAG ENTRE O MERCADO ACIONÁRIO BRASILEIRO E O MERCADO DE ADRs: uma revisão metodológica
}

Brasília - DF

Setembro / 2009 


\section{O EFEITO LEAD-LAG ENTRE O MERCADO ACIONÁRIO BRASILEIRO E O MERCADO DE ADRs: uma revisão metodológica}

Trabalho de Conclusão de Curso apresentado ao Departamento de Administração como requisito parcial à obtenção do título de Bacharel em Administração.

Professor Orientador: Me. José Carneiro da Cunha Oliveira Neto

$$
\text { Brasília - DF }
$$

Setembro / 2009 
Nakamura, Rafael Marques.

O Efeito Lead-Lag entre o Mercado Acionário Brasileiro e o Mercado de ADRs: Uma Revisão Metodológica / Rafael Marques Nakamura. - Brasília, 2009.

57 f.: il.

Monografia (bacharelado) - Universidade de Brasília, Departamento de Administração, 2009.

Orientador: Prof. Me. José Carneiro da Cunha Oliveira Neto, Departamento de Administração.

1. Efeito lead-lag. 2. American Depositary Receipts (ADRs). 3. Bolsa de Valores de São Paulo (Bovespa). I. O Efeito Leadlag entre o Mercado Acionário Brasileiro e o Mercado de ADRs: uma revisão metodológica. 


\title{
O EFEITO LEAD-LAG ENTRE O MERCADO ACIONÁRIO BRASILEIRO E O MERCADO DE ADRs: uma revisão metodológica
}

\author{
A Comissão Examinadora, abaixo identificada, aprova o Trabalho de Conclusão \\ do Curso de Administração da Universidade de Brasília do aluno
}

\section{Rafael Marques Nakamura}

Me. José Carneiro da Cunha Oliveira Neto Professor-Orientador

Esp. Welandro Damasceno Ramalho, Professor-Examinador
Prof. Guilherme Junger

Professor-Examinador 


\title{
RESUMO
}

O presente trabalho tem por objetivo identificar, por meio da revisão da literatura de artigos científicos, a existência do efeito lead-lag entre as ações de empresas listadas na Bolsa de Valores de São Paulo (Bovespa) e seus respectivos recibos depositários no mercado norteamericano - ADRs - listados na Bolsa de Valores de Nova York (NYSE), ou seja, buscou-se entender se os movimentos de elevação e queda de um mercado são seguidos, em média, por variações similares no outro. A confirmação da existência de tal efeito acarretaria em possibilidades de prever os movimentos do preço de uma ação, gerando possibilidades de auferir lucros anormais, ignorados os custos de transação. Dessa maneira, a proposição da Hipótese de Mercado Eficiente - HME - de que as variações de um preço no mercado acionário seguem um processo estocástico, ou seja, aleatório, poderia ser rejeitada. $\mathrm{O}$ estudo compreendeu diversos artigos científicos nas áreas de bolsas de valores, American Depositary Receipts (ADRs), integração e segmentação de mercados, teoria da arbitragem, Hipótese de Mercado Eficiente, teoria da assimetria e efeito lead-lag. Os trabalhos científicos foram escolhidos pelos critérios de relevância, profundidade na abordagem do assunto e ano de sua elaboração. $\mathrm{O}$ trabalho apresentou também a metodologia proposta pelas pesquisas nas áreas de integração do mercado acionário brasileiro e o mercado de ADRs e de efeito lead-lag entre as bolsas de valores de São Paulo e de Nova York. Coeficiente de correlação de Pearson, modelo de regressão linear com Mínimos Quadrados de Dois Estágios (TSLS) e Modelo Vetor de Correção de Erros (VECM) foram algumas das metodologias aqui explicadas com o intuito de dar base aos resultados apresentados. No fim, conclui-se que a literatura aponta para a existência do efeito entre os mercados brasileiro e de ADRs, uma vez que as oportunidades de arbitragens identificadas entre os dois mercados ocorreriam em virtude de uma pequena defasagem temporal.

\author{
1. Efeito Lead-Lag \\ 2. American Depositary Receipts (ADRs) \\ 3.Bovespa
}




\section{LISTA DE ABREVIATURAS E SIGLAS}

ADRs - American Depositary Receipts

BDRs - Brazilian Depositary Receipts

BM\&F - Bolsa de Mercados e Futuros

Bovespa - Bolsa de Valores de São Paulo

CBLC - Companhia Brasileira de Liquidação e Custódia

CVM - Comissão de Valores Mobiliários

DJIA - Dow Jones Industrial Average

DRs - Depositary Receipts

FDRs - French Depositary Receipts

FTSE - Financial Times Stock Exchange

GDRs - Global Depositary Receipts

HME - Hipótese do Mercado Eficiente

IDRs - International Depositary Receipts

NASDAQ - National Association of Securities Dealers Automated Quotations

NYSE - New York Stock Exchange

OLS - Ordinary Least Squares (Mínimos Quadrados Ordinários)

OTC - Over the Counter

QIB - Qualified Investors Buyer

S\&P - Standard and Poor's 500

SEC - Securities and Exchange Commission

SFN - Sistema Financeiro Nacional

TSLS - Two-Stage Least Squares (Mínimos Quadrados de Dois Estágios)

USGAAP - United States Generally Accepted Accounting Principles

VAR - Vetores Auto-Regressivos

VECM - Vetor de Correção de Erro (Vector Error Correction Model)

WFE - World Federation of Exchanges 


\section{SUMÁRIO}

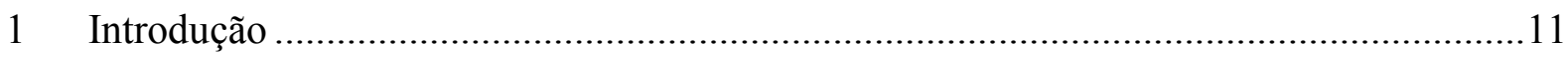

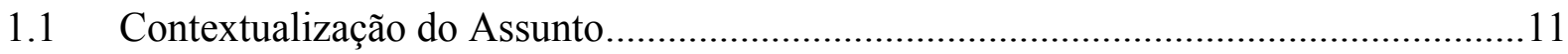

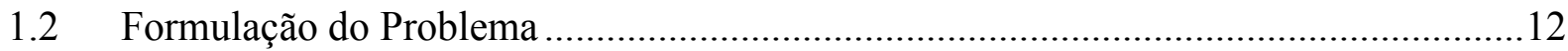

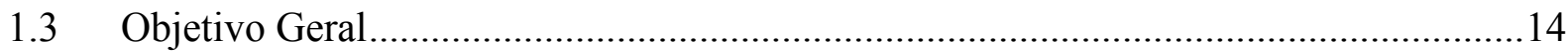

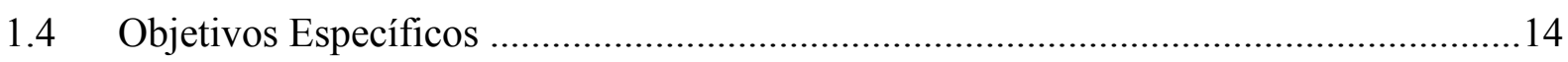

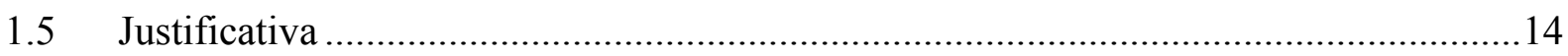

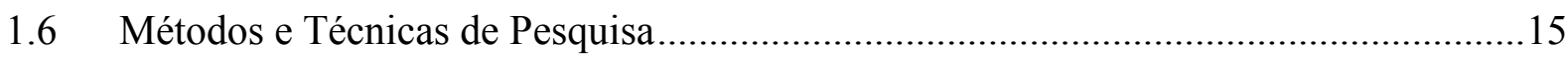

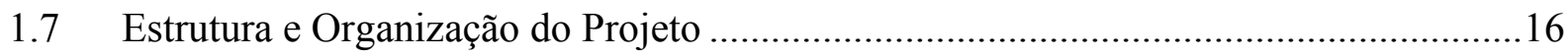

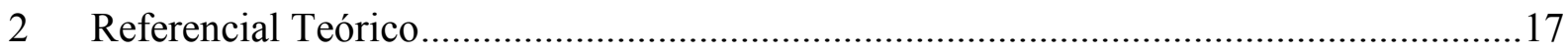

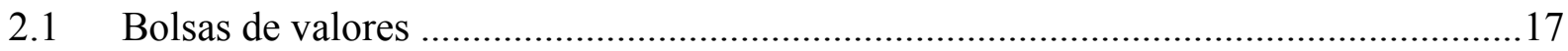

2.1.1 Bolsa de Valores de São Paulo - Bovespa ……………………………………......17

2.1.2 New York Stock Exchange - NYSE ................................................................. 18

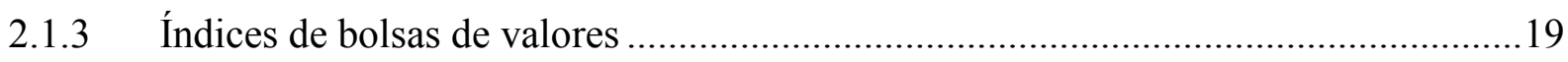

2.2 Depositary receipts (DRs) - Recibos de depósito ......................................................21

2.2.1 Programas de depositary receipts …………………………………………....22

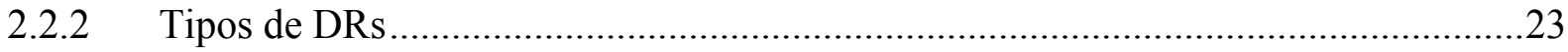

2.2.3 Níveis dos ADRs - American depositary receipts..................................................23

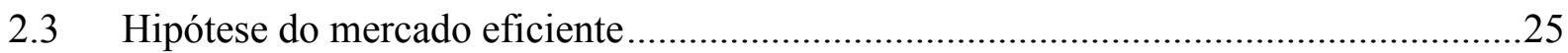

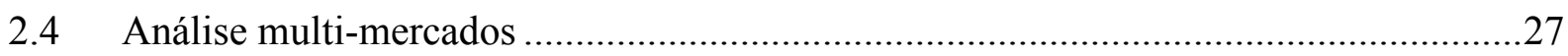

2.4.1 Integração e segmentação de mercados .....................................................................27

2.4.2 Teoria da arbitragem .............................................................................28

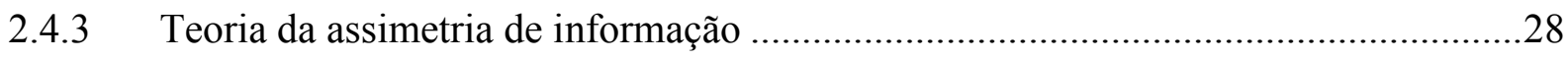

2.4.4 Indicadores de diferença de desenvolvimento entre mercados ...................................29

2.5 Efeito lead-lag ........................................................................................

2.5.1 Evidências empíricas sobre o efeito lead-lag..........................................................31

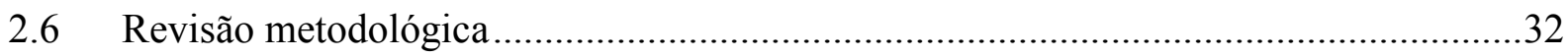

2.6.1 Integração entre o mercado acionário brasileiro e o mercado de ADRs.......................32

2.6.2 Oportunidades de arbitragem entre o mercado brasileiro e o mercado de ADRs.......35

2.6.3 Efeito lead-lag entre os mercados acionários norte-americano e brasileiro ................36

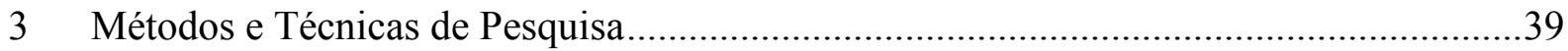

3.1 Tipo e descrição geral da pesquisa..............................................................................39 


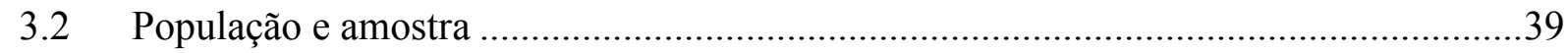

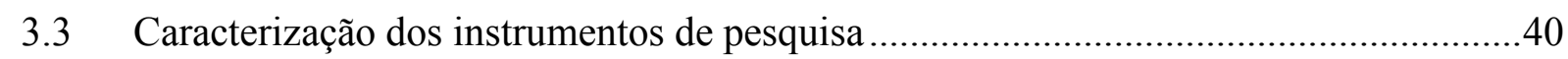

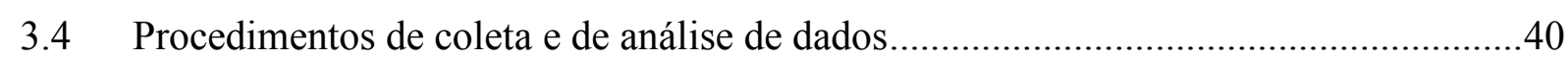

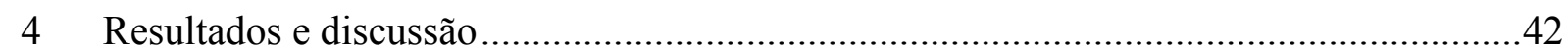

4.1 Estudos sobre a integração de mercados.....................................................................42

4.1.1 Resultados sobre os testes de correlação de Pearson .....................................................42

4.2 Resultados sobre os testes de oportunidade de arbitragem.............................................45

4.3 Efeito lead-lag entre o mercado acionário brasileiro e norte-americano..........................46

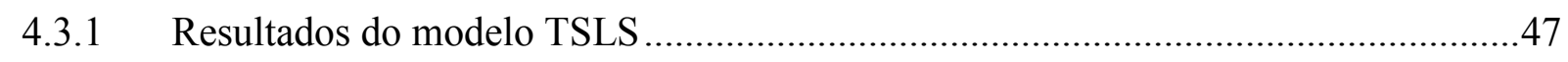

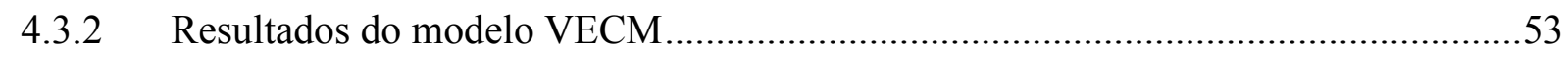

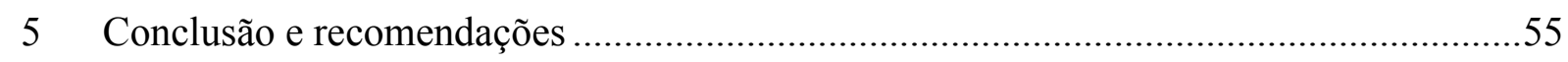




\section{INTRODUÇÃ̃O}

O presente capítulo busca introduzir o tema que será discutido no trabalho de pesquisa. Ele está dividido em contextualização do assunto, a formulação do problema, os objetivos geral e específicos, a justificativa, os métodos e técnicas de pesquisa e a estrutura e organização do trabalho.

\subsection{Contextualização do Assunto}

Os avanços tecnológicos na informática e nos meios de comunicação iniciados no século XX contribuem e continuam contribuindo para a globalização e o estreitamento das relações entre os diversos mercados. Esses atalhos de informações colaboram para o desenvolvimento da integração dos mercados acionários mundiais, que Eiteman et. al. (1994 apud COSTA JUNIOR; LEAL, 1997) definiram como quando dois mercados acionários diferentes possuem o mesmo retorno esperado para ativos de uma mesma classe de risco. O retorno é o percentual de ganho ou perda proporcionada por um ativo em determinado período. O grau de integração entre os grandes mercados mundiais aumentaram nos últimos anos em decorrência do fluxo de informações que se dá de forma rápida.

O aumento na rapidez do fluxo mundial de informações trouxe conseqüências para o mercado, que teve que se adaptar a essas mudanças. Uma vez que as informações relevantes demoravam segundos para cruzar o mundo, investidores de diversos países começaram a investir e negociar ações do mundo inteiro, a fim de diversificarem suas carteiras, minimizarem seus riscos e aumentarem seus lucros.

Hoje em dia, a integração dos mercados é tão grande que, um evento de grande relevância dentro de um mercado pode influenciar mercados do mundo inteiro, como é o caso do atentado terrorista de 2001 e a queda da Bolsa de Valores de Xangai em janeiro de 2008, que derrubou os mercados de vários países, como o brasileiro e o americano. O processo de 
integração dos mercados acabou tornando-os interdependentes, fazendo-os caminharem juntos.

A Hipótese do Mercado Eficiente - HME - estabelece que os preços das ações não são passíveis de previsão, uma vez que os preços se comportam como um passeio aleatório. Dessa maneira, não seria possível a realização de arbitragem entre mercados, visto a incapacidade de um investidor em determinar o próximo preço de uma ação. No entanto, a HME analisa o mercado como um ente único, enxergando-o como um todo, não entendendo mercados diferentes que possam ser segmentados, ou seja, mercados que não mantém um fluxo de informações entre si. Na prática, não existem mercados que sejam totalmente segmentados, porém mercados cujo fluxo de informação não é completo, ou cujas barreiras de cada mercado dificultam o recebimento dessas informações podem gerar retornos diferentes ou defasagens temporais entre a incorporação dessas informações nos preços dos ativos. As defasagens temporais identificadas entre a incorporação das informações no preço de um ativo compõem o conceito de efeito lead-lag.

O efeito lead-lag é percebido quando há uma relação entre os movimentos de preços de dois mercados, sendo que um deles lidera (lead) e o outro o segue com certa defasagem de tempo (lag). Quando tal efeito é identificado, há uma quebra na HME, visto que passa a ser identificado uma oportunidade de arbitragem e, consequentemente, a possibilidade de auferir lucros anormais.

\subsection{Formulação do Problema}

Uma vez que o conceito de lead-lag é identificado como uma oportunidade de arbitragem e de se auferir retornos anormais de mercados, e visto que seria possível prever os futuros movimentos dos preços dos ativos dentro do mercado defasado, surge o problema que busca descobrir como obter tais ganhos.

Oliveira (2008) realizou um estudo que testava a existência do efeito lead-lag entre o mercado brasileiro e norte-americano, chegando à conclusão de que o primeiro tem seus movimentos em grande parte definidos pelos movimentos do mercado estadunidense em minutos 
anteriores. O estudo tomou como base uma carteira de ações da Bolsa de Valores de São Paulo e a comparou aos movimentos do índice Dow Jones Industrial Average.

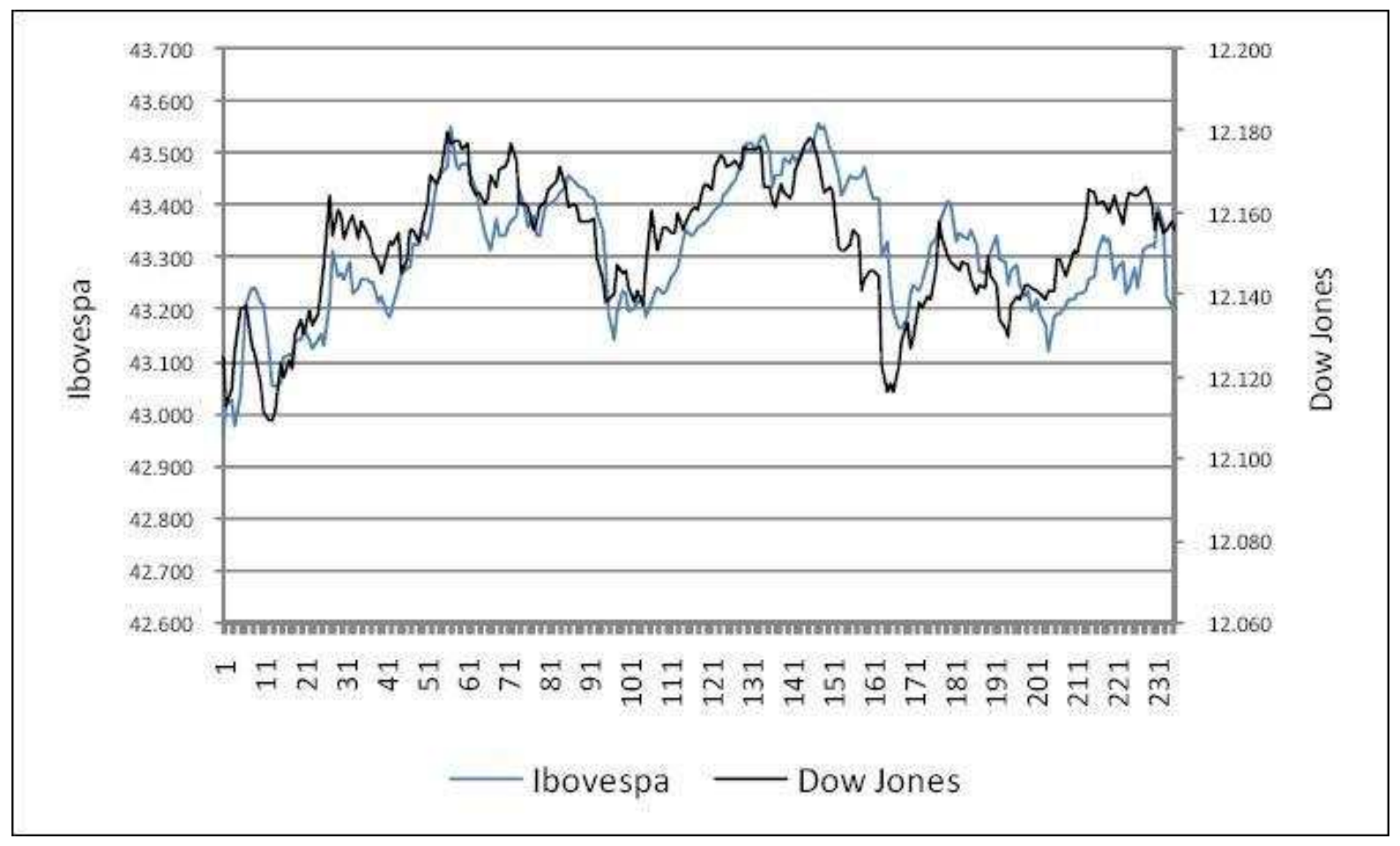

Gráfico 1 - Variação dos Índices Dow Jones e Ibovespa - 15/03/2007, por minuto.

Fonte: Oliveira (2008)

Concomitantemente aos estudos sobre efeito lead-lag entre os diferentes mercados, diversos autores como Camargos et al. (2003); Matsumoto e Borges (2004); De Medeiros e Lima (2006) estudaram o grau de integração e as oportunidades de arbitragem entre os dois mercados. Entretanto, o objeto de estudo desses autores no mercado norte-americano eram os recibos depositários das ações brasileiras - ADRs - que são negociados dentro da Bolsa de Nova York.

Portanto, a partir dessas duas linhas de pesquisa supracitadas, surge a necessidade de um estudo que teste a existência do efeito lead-lag entre o mercado acionário brasileiro e o mercado de ADRs, uma vez que tais oportunidades de arbitragem identificadas entre os dois mercados podem estar diretamente correlacionadas com a defasagem temporal que caracteriza o efeito lead-lag e que permite a obtenção de lucros anormais.

Portanto, o presente estudo busca responder a pergunta: É possível identificar, sob as óticas de diversos autores, a correlação de efeito lead-lag entre o mercado acionário brasileiro e o mercado de ADRs? 


\subsection{Objetivo Geral}

Este estudo tem como objetivo perceber se a literatura aponta para a existência do efeito entre esses dois mercados, por meio da revisão e análise crítica da literatura já escrita até aqui sobre efeito lead-lag e integração entre o mercado brasileiro e o mercado de ADRs.

\subsection{Objetivos Específicos}

- Verificar a existência do efeito lead-lag entre o mercado acionário brasileiro e o mercado norte-americano;

- Verificar a correlação e o grau de integração entre o mercado de ADRs e o mercado brasileiro;

- Concluir, a partir da literatura científica existente sobre o assunto, se existe a possibilidade de se auferir ganhos anormais em decorrência dos efeitos lead-lag.

\subsection{Justificativa}

Vários estudos relacionados à integração do mercado acionário brasileiro e outros mercados estrangeiros, especialmente o norte-americano, já foram realizados no Brasil, como é o caso de Costa e Junior e Leal (1997; 1998), Groppo e Bacchi (2005), Bruni e Famá (2003), entre outros que não só buscavam identificar os graus de correlação entre os mercados como também oportunidades de arbitragem. Oliveira (2008), já foi mais além, buscando identificar não somente a integração entre os mercados brasileiro e estadunidense, mas também a existência de uma relação de liderança e defasagem entre esses mercados, fenômeno esse denominado lead-lag. 
No entanto, para esse último estudo, os resultados do efeito lead-lag encontrados foram referentes a uma carteira com as doze ações com maior ponderação na Bovespa e o índice Dow Jones, implicando em um resultado generalizado.

O presente estudo se compromete a explorar as relações de lead-lag entre papéis que possuem características muito semelhantes e que se encontram dentro de uma mesma classe de risco, que são o caso das ações e seus respectivos ADRs. Tal análise se faz importante, uma vez que, comprovada a existência do efeito entre os dois mercados, a elaboração de novas estratégias que se utilizem da defasagem temporal e da possibilidade de previsão de movimentos dos mercados se torna possível, permitindo a obtenção de lucros anormais.

\subsection{Métodos e Técnicas de Pesquisa}

Para a realização da pesquisa será utilizada a pesquisa bibliográfica que consiste basicamente na busca de informações e seleção de documentos que se relacionam com o problema de pesquisa (MACEDO, 1994). Dessa maneira, espera-se realizar um estudo exploratório com uma profunda revisão da literatura dos diversos autores relevantes acerca do tema proposto.

Será realizada uma seleção de diversos artigos científicos e livros na área de mercado financeiro, com foco nos trabalhos sobre efeito lead-lag e integração entre os mercados brasileiro e norte-americano. Para isso, a elaboração de um roteiro com a relação dos principais itens a serem pesquisados nos trabalhos científicos se faz imprescindível, a fim de que uma triagem nos documentos seja realizada, mantendo somente aquilo que se faz relevante para o estudo.

Uma análise metodológica dos trabalhos escolhidos será realizada, tendo seus respectivos resultados posteriormente divulgados. Espera-se, dessa maneira, que as conclusões alcançadas pelos teóricos da área sejam capazes de apontar a existência do efeito lead-lag entre o mercado brasileiro e de ADRs. 


\subsection{Estrutura e Organização do Projeto}

O presente projeto foi dividido em seis partes.

A primeira parte aborda a introdução ao tema, levando em consideração sua contextualização, a formulação do problema de pesquisa, os objetivos geral e específicos do estudo, sua justificativa e relevância, os métodos e técnicas de pesquisa que serão utilizados e a estrutura do trabalho.

A segunda parte consiste no referencial teórico do tema abordado e sua respectiva referência bibliográfica. Foi dividida em cinco seções, que buscam englobar todo o conhecimento necessário para compreensão e dar credibilidade ao trabalho, sendo elas: Bolsas de valores; Depositary receipts - Recibos de depósito; Hipótese do mercado eficiente; Análise de multimercados e; Efeito lead-lag.

A terceira parte consiste nos métodos e técnicas de pesquisa, contendo o processo que será utilizado para coleta, tratamento de resultados e alcance dos objetivos propostos. Nessa parte, encontram-se as subdivisões de tipo e descrição geral da pesquisa; caracterização da área estudada; população e participantes do estudo; caracterização dos instrumentos de pesquisa e; procedimentos de coleta e análise de dados.

A quarta parte do estudo apresentará os resultados e as conclusões alcançadas pelos teóricos em seus respectivos estudos, além de trazer uma discussão sobre cada um deles.

$\mathrm{Na}$ quinta parte, uma conclusão de todo o trabalho será realizada, buscando responder à pergunta da pesquisa e apresentando os motivos que embasam o entendimento alcançado. Além disso, recomendações para estudos posteriores também serão apresentados nessa parte do trabalho. 


\section{REFERENCIAL TEÓRICO}

\subsection{Bolsas de valores}

As bolsas de valores são instituições administradoras de mercados, criadas para facilitar a negociação de ações no mercado secundário. Sua principal função é criar as condições para os investidores comprarem e venderem os valores de companhias abertas com segurança e eficiência (ASSAF NETO, 2009).

Dentro das bolsas de valores, são realizadas sessões durante as quais são realizadas as transações de compra e venda de ações, em geral, por meio de corretores. É muito importante que todos os participantes do pregão tenham acesso aos dados de todos os preços de negociação das ações, uma vez que o acesso privilegiado deles por parte de alguns investidores geraria uma vantagem em relação àqueles que, por algum motivo, não têm. Portanto, torna-se responsabilidade das bolsas de valores a divulgação rápida e eficiente dos resultados de todas as transações realizadas em seu âmbito (ASSAF NETO, 2009).

\subsubsection{Bolsa de Valores de São Paulo - Bovespa}

A Bolsa de Valores de São Paulo - Bovespa - é a maior bolsa de valores da América Latina, chegando a envolver cerca de 70\% de todo volume negociado na região. Ela surgiu em 1890, a partir do desenvolvimento da Bolsa Livre (BOVESPA, 2008).

Em 1845, o Brasil inicia sua história nas bolsas de valores com a criação da Bolsa de Valores do Rio de Janeiro. Mais tarde, outras bolsas apareceram, como a Bolsa Livre em 1890, que passou a denominar-se Bolsa de Fundos Públicos de São Paulo em 1895 e, finalmente Bolsa de Valores de São Paulo - Bovespa - em 1960. Em 2000, a Bovespa realizou o acordo de integração das nove bolsas de valores existentes, concentrando toda a negociação de ações no país (ASSAF NETO, 2009). Por fim, em 2007, a Bovespa realizou uma reestruturação 
societária que culminou em sua desmutualização e na criação da Bovespa Holding, que possui a própria Bovespa e a Companhia Brasileira de Liquidação e Custódia (CBLC) como subsidiárias integrais de capital fechado (OLIVEIRA, 2008). Em 26 de Outubro de 2007, a Bovespa Holding abre seu capital na própria bolsa, lançando o equivalente US\$ 3,2 bilhões em ações (OLIVEIRA, 2008). Por fim, em 8 de Maio de 2008, a Bovespa se funde com a Bolsa de Mercadorias e Futuros (BM\&F), transformando-se em Bolsa de Valores, Mercadorias e Futuros, denominada BM\&FBovespa.

A Bolsa de Valores de São Paulo é uma entidade integrante do Sistema Financeiro Nacional (SFN) e é fiscalizada pela Comissão de Valores Mobiliários (CVM) (ASSAF NETO, 2009).

\subsubsection{New York Stock Exchange - NYSE}

A Bolsa de Valores de Nova York foi fundada em 1792 por vinte e quatro agentes financeiros que assinaram o acordo de Buttonwood, realizado com o fim de criar a New York Stock \& Exchange Board e estabelecer as regras de comercialização de ações. Hoje, a Bolsa de Valores de Nova York é a maior do mundo e conta com um volume anual de transações na ordem de US\$ 21 bilhões. Em outubro de 2008, a capitalização combinada de todas as empresas domésticas listadas na NYSE era de US\$10,1 trilhões. (NYSE, 2009).

A NYSE passou por duas grandes crises em 1929. Em 24 de outubro desse ano, ocorreu o que ficou conhecido como a "Segunda-Feira Negra", quando, no mesmo dia, o mercado perdeu $12,8 \%$ de seu valor. No dia seguinte, o mercado caía mais $11,7 \%$, episódio chamado também de "Terça-Feira Negra". Com a crise de 1929, o mercado sofreu uma queda de 30\% somente nos primeiros seis dias e alcançou uma desvalorização de mercado de 90\% em Julho de 1932. Com isso, foram necessários 25 anos para que a bolsa recuperasse seus antigos patamares. No entanto, em 19 de outubro de 1987, ocorria uma nova "Segunda-Feira Negra", em que o mercado acionário americano registrava uma queda de aproximadamente $23 \%$ de seu valor, a maior queda do índice Dow Jones num só dia (OLIVEIRA, 2008). 


\subsection{3 Índices de bolsas de valores}

O índice de uma bolsa de valores é o valor que capta os movimentos da respectiva bolsa, buscando refletir o comportamento do mercado dentro de um intervalo de tempo. Tal valor é representado pelo desempenho médio dos preços de uma carteira de ações que, a partir dela, acredita-se expressar de maneira fidedigna o comportamento da bolsa. $\mathrm{O}$ valor absoluto do índice da carteira representa seu valor de mercado dentro da respectiva bolsa, sendo suas variações verificadas periodicamente, a fim de comparar valores e identificar aumentos e quedas, que representam sua lucratividade (ASSAF NETO, 2009).

Para a composição de uma carteira que reflita os movimentos da bolsa de maneira legítima, devem ser priorizadas as ações que sejam sensíveis aos movimentos do mercado e que tenham grande representatividade nos negócios realizados na bolsa de valores, ou seja, que atinjam um percentual expressivo do volume negociado no mercado. Para cada ação eleita, é atribuído um peso, que representa sua importância no volume de negócios da carteira (ASSAF NETO, 2009).

Os índices das Bolsas também são bastante úteis para representar as tendências gerais da economia, por meio dos investimentos em ações. Essas variações periódicas conseguem esboçar ciclos que caracterizam o funcionamento da economia, o que cria as expectativas dos investidores em relação a seu comportamento esperado (ASSAF NETO, 2009).

\subsubsection{O índice Ibovespa}

O Ibovespa é o principal índice de desempenho das cotações das ações negociadas na Bolsa de Valores de São Paulo. O indicador foi criado em 1968 e não teve sua metodologia alterada desde então. Consiste em uma carteira teórica de ações composta por sessenta e quatro empresas, que correspondem a 80\% do volume negociado na Bovespa. Quando foi criada, seu valor base era de 100 pontos e sua pontuação atual representa a variação sofrida pela carteira desde a data de sua criação (ASSAF NETO, 2009). No entanto, sem alterações metodológicas, o índice sofreu uma divisão por 100 em 1983 e dez divisões por 10 entre 1985 e 1997 (OLIVEIRA, 2008). 
É importante ressaltar também que o índice Ibovespa não considera somente a valorização das ações, mas também consegue refletir de maneira eficaz o impacto da distribuição dos proventos e juros sobre o capital próprio (OLIVEIRA, 2008).

Além disso, o indicador passa por uma reavaliação quadrimestral, com o objetivo de identificar o desempenho dos papéis compositores da carteira teórica e trocar aqueles que perderam parte de sua participação na bolsa por outros, sempre buscando elaborar uma carteira que represente cerca de $80 \%$ do volume comercializado no mercado a vista nos últimos 12 meses, além de apresentar, no mínimo, 80\% de presença nos pregões da bolsa no mesmo período.

\subsubsection{Outros índices}

Apesar de o Ibovespa ser o principal e mais utilizado índice de desempenho da Bolsa de Valores de São Paulo, há no Brasil outros importantes indicadores que buscam refletir o comportamento do mercado a partir de diversos critérios. Entre esses indicadores, podemos encontrar índices com propostas e metodologias parecidas com a do Ibovespa, como o IBX Índice Brasil, que representa uma carteira teórica composta pelas 100 ações de maior negociação na Bovespa, ou seja, com maior volume financeiro e número de negócios; e o IBX-50, que possui as mesmas características do IBX, porém, utilizando-se somente das 50 ações mais negociadas; além de alguns índices mais específicos, tais como o IEE, que representa a lucratividade das companhias que operam no segmento de energia elétrica; o IGC, que analisa o desempenho de uma carteira formada somente por ações de empresas que possuem bons níveis de Governança Corporativa; e o ISE, que avalia somente o desempenho das ações de empresas rentáveis, sustentáveis e com responsabilidade social. Esse último índice foi lançado pela Bovespa em 2005, seguindo uma tendência mundial das Bolsas de Valores de desenvolver e divulgar índices de empresas socialmente responsáveis.

Além dos outros índices encontrados no Brasil, podemos citar ainda os indicadores das principais Bolsas de Valores do mundo. No caso da Bolsa de Valores americana (NYSE), o índice mais utilizado é o Dow Jones Industrial Average - DJIA - ou simplesmente Dow Jones, que representa uma carteira teórica composta por 30 blue-chip ações norte-americanas. É o indicador de desempenho de uma Bolsa mais antigo do mundo e praticamente segue a 
mesma metodologia de quando foi criada, em 1884. Como o próprio nome diz, o índice representava a média aritmética das 30 ações listadas, ou seja, a soma de seus preços dividida pelo número de ações dessas empresas no mercado (OLIVEIRA, 2008). No entanto, quando as ações sofriam um split ou mesmo um inplit, o índice deixava de apresentar a média com fidelidade. Para isso, foi desenvolvido um fator denominado divisor, que entra no lugar do denominador da equação supracitada, buscando corrigir tais discrepâncias (ASSAF NETO, 2009).

Dentro da NYSE, além do Dow Jones, ainda há o Standard \& Poor's 500 (S\&P 500), que representa uma carteira teórica composta por 500 ações da Bolsa de Valores norte-americana que são calculadas por meio de uma ponderação do valor de mercado da empresa; e o NASDAQ, que, por meio de sistema homônimo que lista e publica cotações principalmente de ações de empresas envolvidas no ramo da tecnologia, cria uma carteira teórica com ações negociadas dentro desse sistema.

Por fim, podemos citar o índice Nikkei, que representa o desempenho de 200 ações da Bolsa de Valores de Tóquio selecionadas por critérios de negociação e participação no mercado; e o FTSE-100, que representa a média geométrica entre as 100 ações mais representativas da Bolsa de Valores de Londres.

\subsection{Depositary receipts (DRs) - Recibos de depósito}

Com o intuito de atrair recursos estrangeiros para o mercado doméstico, empresas se dispõem de um instrumento denominado Depositary Receipts (DRs), que consistem em recibos de depósitos lastreados em uma ou mais ações para serem vendidos em mercados de outros países (ASSAF NETO, 2009). Os DRs podem representar uma ou várias ações ordinárias ou preferenciais, além de também poder representar somente os direitos sobre as ações obtidas por um contrato derivativo. Esses papéis possuem todas as características das ações que representam, assim como todos os direitos adquiridos pelos acionistas do país de origem. Os DRs mais comuns são os ADRs, que significam American Depositary Receipts, ou seja, são os recibos de depósito emitidos nos Estados Unidos. No entanto, ainda existem os BDRs 
(Brazilian Depositary Receipts) e os GDRs (Global Depositary Receipts) (ANDREZO e LIMA, 1999).

Uma importante característica do mercado de DRs é que os bancos que emitem esses títulos, chamados de bancos depositários, garantem uma troca segura e imediata desses títulos em ações e vice-versa, facilitando a convertibilidade dos DRs entre o mercado de origem e o mercado estrangeiro. Uma vez que tal operação pode ser facilmente realizada, oportunidades de arbitragem surgem por meio da taxa de câmbio e da cotação dos papéis nos mercados (ASSAF NETO, 2009; MEDEIROS, 2006).

A emissão de DRs surgiu como uma oportunidade para empresas que buscam aumentar sua captação de recursos. Uma vez que há o interesse de investidores estrangeiros em buscarem novas oportunidades nas economias de países emergentes, empresas se utilizam desse recurso para atrair novos investimentos (ROSA, 2004).

\subsubsection{Programas de depositary receipts}

Segundo Andrezo e Lima (1999), os programas de DRs podem ser divididos em dois grupos: patrocinados e não-patrocinados.

Os programas patrocinados são os mais comuns no que tange a iniciativa no processo de emissão do título. Nesse programa, a própria empresa que terá suas ações representadas por uma DR estabelece um acordo com o banco depositário, que atuará como agente exclusivo da transferência. A empresa assume todos os custos de implementação do programa, além da responsabilidade de manter o fluxo de informações aos investidores estrangeiros. O custo de emissão do título é de responsabilidade do investidor final.

Nos programas não-patrocinados, o ingresso da empresa no mercado estrangeiro se dá de maneira involuntária. Nesse programa, os títulos são emitidos por um ou mais bancos depositários sem o consentimento da empresa, cabendo à instituição emissora a responsabilidade do fluxo de informações da empresa aos investidores. (ROSA, 2004). Como a empresa emissora não possui controle sobre as informações fornecidas aos investidores, tal modalidade tem caído em desuso nos últimos anos. 


\subsubsection{Tipos de DRs}

Dentre os tipos mais conhecidos de DRs estão os ADRs - American Depositary Receipts negociados exclusivamente no mercado norte-americano. No entanto, ainda podem ser citados os títulos próprios de alguns países como os BDRs - Brazilian Depositary Receipts negociados no Brasil, e os FDRs - French Depositary Receipts - negociados na França; ou ainda os DRs negociados em mais de um país como os IDRs - International Depositary Receipts - negociados na Europa e os GDRs - Global Depositary Receipts - emitidos somente por investidores institucionais em certos mercados. De uma maneira geral, esses últimos requerem menos exigências em termos de disclosure (abertura) em relação aos ADRs. ADRs exigem o cumprimento de rígidas regras do mercado de capitais americano, demonstrando bons fundamentos de desempenho econômico e financeiro, além de maior transparência das informações e respeito amplo aos direitos dos acionistas (ASSAF NETO, 2009). Mesmo assim, os recibos de depósito americanos são os mais utilizados, em razão de sua maior capitalização e da expressividade dos Estados Unidos em relação aos demais mercados (CAMARGOS; GOMES; BARBOSA, 2003).

\subsubsection{Níveis dos ADRs - American depositary receipts}

Uma vez que o presente estudo busca analisar o mercado de ADRs, é importante mencionar que o mercado norte-americano possui quatro níveis de recibos de depósitos, que se diferenciam em termos de meios de negociação, exigências de transparência e adequação às normas da SEC (Securities and Exchange Commission, equivalente à CVM no mercado brasileiro) e observância dos USGAAP (United States Generally Accepted Accounting Principles: Princípios Contábeis Norte-Americanos Geralmente Aceitos) (CAMARGOS; GOMES; BARBOSA, 2003).

ADR do nível I, também chamado de Pink Sheet, é a maneira mais simples e barata de entrar no mercado norte-americano. Títulos desse nível são negociados em mercados de balcão locais (Over the Counter - OTC), portanto não há captação efetiva de novos recursos por parte da empresa emissora nem alteração na posição patrimonial da empresa. A única 
instituição capaz de obter recursos por meio da negociação de ADRs de nível I é o banco custodiante (CAMARGOS; GOMES; BARBOSA, 2003). Além disso, ADRs desse nível podem ser negociadas sem fornecer à SEC o disclosure completo e sem se adaptar aos USGAAP. Dessa maneira, essas empresas podem continuar publicando suas informações somente nos padrões exigidos pelo país de origem, não necessitando se adaptar aos padrões contábeis americanos. Em contrapartida, o OTC market é um mercado de baixa liquidez, em que os ADRs nele negociados não oferecem a possibilidade de investidores participarem de novas emissões de ações que a empresa em questão venha a fazer, uma vez que isso exigiria o registro na SEC (LAMEIRA; NESS JR; SOARES, 2007).

Assim como os de primeiro nível, ADRs de nível II não captam recursos para a empresa emissora do título, permitindo somente ao banco custodiante fazê-lo. No entanto, esses ADRs, também chamados de Listers, conseguem ser negociados nas bolsas americanas, visto que preencham seus respectivos requisitos. Para ADRs desse nível, as empresas devem registrarse junto à SEC, disponibilizar ao mercado norte-americano seus relatórios de administração e todas e quaisquer informações tornadas públicas em seu país de origem, além de elaborar suas demonstrações financeiras e revisões de auditoria em padrões americanos. O mercado onde os ADRs de nível II são negociados apresentam grande liquidez e visibilidade para a empresa (LAMEIRA; NESS JR; SOARES, 2007).

ADRs de nível III, por sua vez, permitem à empresa captar recursos pela oferta pública desses títulos no mercado norte-americano, lastreado pela emissão de novas ações no mercado de origem. Para que as empresas possam lançar ADRs desse nível, elas devem se registrar por completo na SEC, que justifica por que esses títulos também se chamam Fully Registered, e devem adaptar suas demonstrações financeiras à USGAAP. ADRs de nível III são negociados no mesmo mercado que os de nível II, consequentemente representando liquidez e visibilidade para a empresa emitente, no entanto, seus custos para atender às exigências são maiores que nos níveis anteriores (CAMARGOS; GOMES; BARBOSA, 2003).

Por fim, existem os ADRs que são emitidos no mercado norte-americano segundo as normas 144A (Rule 144A), que permite a captação de recursos de certas empresas por meio de investidores institucionais qualificados (Qualified Investor Buyer - QIB). Em virtude do volume que negociam, esses investidores são considerados qualificados o suficiente para não necessitarem de proteção da SEC. Logo, empresas que negociam suas ADRs utilizando-se da norma 144A não necessitam de registro na SEC nem de adaptação de suas demonstrações 
financeiras aos padrões americanos, mas somente de um "memorando de ofertas", baseado no relatório anual completo mais recente emitido pela empresa, além de se comprometer a manter o fornecimento de informações aos investidores estrangeiros na mesma frequência e conteúdo do fornecido aos nacionais. Do ponto de vista legal, para que uma empresa consiga captar recursos por meio da norma 144A, a empresa precisa cumprir somente as exigências para a emissão de um ADR de nível I. Os ADRs dessa categoria são colocados no mercado por meio de bancos que os vendem aos investidores institucionais, o que é considerado uma desvantagem desse tipo, pois a empresa perde sua visibilidade, ficando conhecida somente dentro de um universo restrito de investidores (CAMARGOS; GOMES; BARBOSA, 2003).

Andrezo e Lima (1999) identificaram que, em geral, as empresas brasileiras iniciam suas operações dentro dos Níveis I e II, migrando para níveis superiores à medida que percebem uma aceitação do mercado. Portanto, as empresas brasileiras que emitem ADRs buscam ampliar seu centro de liquidez, tornar-se conhecidas em outros mercados e conquistar a confiança do investidor nacional.

\subsection{Hipótese do mercado eficiente}

Mercados financeiros são sistemas complexos em que as informações relativas a uma empresa emissora de ações influenciam os investidores que, por meio dos instrumentos de compra e venda, determinam o melhor preço para o respectivo ativo.

A Hipótese do Mercado Eficiente (HME) tem como enunciado que um mercado somente é eficiente quando todas as informações disponíveis são processadas e refletidas imediatamente em forma de novos preços para os ativos (MANTEGNA e STANLEY, 2000), o que impossibilitaria a realização de lucros acima da média de mercado por parte dos investidores, devido ao curto lapso de tempo entre a divulgação das informações e sua incorporação pela ação, que ocorreria antes que o processo da transação pudesse ser efetuado.

Vários matemáticos já defenderam a HME, como Bachelier em 1900 (BERNSTEIN, 2007), que propôs que os preços de um ativo em um mercado especulativo passam por um processo estocástico conhecido como martingale. O conceito de martingale é que o valor esperado de 
uma ação em um período é o mesmo no período seguinte. Dessa maneira, seria impossível prever o valor futuro de uma ação, confirmando a proposição da HME (MANTEGNA; STANLEY, 2000).

A HME é dividida em três formas - Fraca, Semi-Forte e Forte - que são diferenciadas em relação à relevância de cada tipo de informação no processo de precificação dos ativos. A forma Fraca da HME afirma que os preços correntes dos ativos incorporam todas as informações dos preços passados, dessa maneira, não permitindo a previsão da cotação futura de um ativo por meio da análise de sua série histórica. Portanto, a forma Fraca da HME tira o sentido da análise técnica de uma ação, uma vez que a fonte de informações do analista, que é a série histórica da ação, não seria capaz de fornecer informações que lhe permitisse prever seu valor futuro (OLIVEIRA, 2008).

A forma Semi-Forte da HME segue o mesmo raciocínio da forma Fraca, porém a complementa. De acordo com a forma Semi-Forte, o mercado não somente incorpora as informações dos preços antigos como também absorve toda informação pública relativa à instituição emissora da ação. Entre essas informações, estariam os balanços comerciais, os demonstrativos financeiros próprios e dos concorrentes, variáveis macro-econômicas, entre outras.

Por fim, a forma Forte afirma que não somente as informações públicas são incorporadas no preço do ativo, mas também as internas da empresa emissora. Tal hipótese se basearia na idéia de que membros internos da empresa, em posse de informações privilegiadas, comprariam e venderiam ações no mercado, incorporando tais informações em seu preço (OLIVEIRA, 2008).

Eugene Fama (1970 apud Camargos; Gomes; Barbosa, 2003), formulador original da proposição, determinou as condições suficientes para a verificação da HME. Tais condições seriam:

1.1 A inexistência de custos de transação na negociação de títulos;

1.2 A gratuidade e fácil acesso de todas as informações do mercado a todos seus participantes; e

1.3 As mesmas antecipações dos investidores quanto às performances futuras dos títulos. 
No entanto, Mussa et al. (2008) afirmam que tais condições são suficientes para a verificação da existência de mercados eficientes, mas não são necessárias, visto que custos de transição elevados não impediriam um ativo de incorporar toda informação disponível.

Um argumento contra o conceito de Mercado Eficiente deriva do fato de que a HME pressupõe que o mercado é um ente único, não considerando a existência de diferentes mercados. No entanto, sabe-se que existem diversos mercados, com diferentes características e graus de desenvolvimento (OLIVEIRA, 2008).

\subsection{Análise multi-mercados}

\subsubsection{Integração e segmentação de mercados}

A integração de mercados é percebida quando dois mercados, após o ajustamento aos riscos cambial e tributário, possuem aproximadamente os mesmos retornos esperados para ações de uma mesma classe de risco (EITEMAN; STONEHILL; MUFFET, 1994 apud COSTA JUNIOR; LEAL, 1997). Mercados totalmente integrados, após os ajustes cambiais e de impostos, rigorosamente possuem os mesmos retornos para os mesmos ativos (OLIVEIRA, 2008).

Segmentação, por sua vez, em termos de mercados de capitais de diferentes países, significa o isolamento de um mercado ao fluxo de informações pertinentes aos ativos negociados nos dois mercados por meio de barreiras explícitas ou não (BRUNI e FAMÁ, 2003). No entanto, o fato de dois mercados serem segmentados não se relaciona com o retorno de ativos de nível de risco semelhante. Dois mercados totalmente segmentados podem apresentar retornos parecidos em ativos da mesma classe de risco, no entanto, tal evento não poderia ser identificado como integração de mercados, uma vez que não houve fluxo de informações entre eles relevantes à precificação do ativo.

Tanto em mercados totalmente integrados quando nos totalmente segmentados é impossível a realização de arbitragem. No caso do primeiro, os dois dispõem das mesmas informações e possuem exatamente os mesmos retornos esperados, não permitindo o lapso temporal 
imprescindível para a realização de arbitragem. No segundo caso, mercados totalmente segmentados não possuem relações entre si, impedindo a compra e venda de um ativo nos dois mercados. Apesar disso, na prática, não existem mercados totalmente segmentados, tampouco mercados totalmente integrados, apesar de existirem mercados altamente integrados (OLIVEIRA, 2008).

\subsubsection{Teoria da arbitragem}

Arbitragem pode ser definida como uma operação que visa se aproveitar de desequilíbrios eventuais nos preços de um ativo em diferentes mercados. Por meio da arbitragem, é possível comprar um ativo por um preço em um determinado mercado e vendê-lo em outro por um preço superior, gerando lucro (ASSAF NETO, 2009). Ross, Westerfield and Jaffe (2008) definem a arbitragem como sendo um processo simultâneo de realização de um negócio em um mercado e sua subseqüente realização compensatória em outro mercado com condições mais favoráveis.

Teoricamente, a arbitragem é uma operação que não requer investimento e que é capaz de trazer um lucro seguro para o arbitrador, uma vez que a oportunidade de arbitragem se dá por meio da existência de dois ativos iguais em mercados diferentes e com preços diferentes. No entanto, existem importantes obstáculos na realização de tal lucro, tendo em vista os atritos do mercado e as informações imperfeitas que podem limitar a arbitragem. Os atritos de mercado podem ser percebidos como custos de transação, impostos e restrições à compra de lotes muito pequenos. As informações imperfeitas não podem ser percebidas claramente e envolvem a percepção de se um desvio anormal de preço em detrimento de outro mercado realmente representa uma oportunidade de arbitragem (MEDEIROS e LIMA, 2006).

\subsubsection{Teoria da assimetria de informação}

Para que os participantes de um mercado possam agir de forma eficiente, é necessário que eles tenham as informações corretas e suficientes para auxiliá-los no processo de tomada de 
decisão. No entanto, a falta de informações por parte de alguns agentes do mercado os motivará a agir de forma ineficiente, enquanto aqueles que possuírem as informações completas poderão de negociar os ativos de forma competente. Portanto, essa informação imperfeita é a causa do conceito de assimetria de informações, que é a situação em que os agentes que possuem mais informações que os outros conseguem agir de forma a obter mais ganho (OLIVEIRA, 2008).

A Teoria da Assimetria de Informação possui relação direta com a Hipótese de Mercado Eficiente e a teoria da arbitragem. Existe uma interação entre essa teoria e a HME no fato de que quanto maior for a primeira, menor será a segunda, visto que a falta de informações relevantes suficientes dentro de um mercado especulativo, pode levar o investidor a tomar decisões erradas, o que pode causar uma má precificação dos ativos no mercado ou retardamentos nos ajustes dos preços. Tais informações são interpretadas e assimiladas nos preços dos ativos, causando uma grande diferença de informações entre dois mercados distintos, que são refletidas em termos de uma defasagem de preços, o que oportuniza a arbitragem (CAMARGOS, GOMES e BARBOSA, 2003).

A assimetria de informações pode decorrer de vários fatores, como o acesso privilegiado de insiders a informações relevantes e não disponíveis a todos, assim como o diferente grau de desenvolvimento entre dois mercados.

\subsubsection{Indicadores de diferença de desenvolvimento entre mercados}

De acordo com Oliveira (2008), o grau de desenvolvimento de um mercado pode gerar assimetria de informações, uma vez que mercados mais desenvolvidos possuem maior disponibilidade de informações, oferecendo aos seus agentes mais possibilidades de precificarem seus ativos de forma eficiente, em detrimento de mercados menos desenvolvidos. Para a definição dos níveis de desenvolvimento, são utilizados indicadores, que são utilizados para a realização de comparações.

Um indicador do nível de desenvolvimento é o próprio tamanho dos mercados, em termos de capitalização. A NYSE, por exemplo, tinha uma capitalização de mercado de US\$ 9,363 trilhões em janeiro de 2009, ocupando a primeira posição no ranking das maiores bolsas do 
mundo. A Bovespa, em compensação, tinha uma capitalização de US\$ 0,611 trilhões no mesmo período, ocupando a décima terceira posição no mesmo ranking (WORLD FEDERATION OF EXCHANGES, 2009).

Outro indicador importante para a avaliação do grau de desenvolvimento de um mercado seria o nível de concentração de suas principais empresas. Em 2005, 19 empresas eram responsáveis por $61,3 \%$ do volume negociado na Bovespa, enquanto 91 empresas movimentavam somente $38,2 \%$ das transações da NYSE (ASSAF NETO, LIMA e DE ARAÚJO, 2007).

A existência de um mecanismo de proteção aos acionistas minoritários também indicam o nível de desenvolvimento de um mercado. Mercados mais desenvolvidos normalmente possuem melhores práticas de governança corporativa, o que tende a estender a todos os acionistas as mesmas condições.

Um mercado mais desenvolvido, por causa de seu alto volume de transações, tende a possuir mais investidores profissionais, que possuam mais competência para interpretar informações e aplicá-las sobre o preço dos ativos. Em contrapartida, os agentes dos mercados subdesenvolvidos, que não possuem a mesma capacidade, podem acabar precificando erradamente seus ativos ou, pelo menos, podem gerar um retardamento nos ajustes de preços, a partir do momento que a informação relevante é divulgada (OLIVEIRA, 2008).

Também é pressuposto que a correlação entre o nível de desenvolvimento do mercado e o nível de desenvolvimento do país é positiva, ou seja, quanto mais desenvolvido é um país, mais desenvolvida será sua bolsa. Tal suposição é baseada na eficiência de disseminação das informações globais dentro desses países. Oliveira (2008) encontra dois motivos para explicar porque os países mais desenvolvidos possuem tal eficiência na divulgação de tais informações. Em primeiro lugar, compreende-se que o poder da mídia é muito grande nesses países, tornando a disseminação dessas informações eficaz. Em segundo lugar, a força do idioma, uma vez que a grande maioria das informações de relevância global é divulgada no idioma inglês, favorecendo a assimilação das informações por parte dos países que adotam a língua. Consequentemente, investidores que não dominam o idioma precisam traduzir as informações para depois aplicá-las, o que acaba gerando um intervalo de tempo anormal entre sua divulgação e aplicação. Além disso, investidores não fluentes no idioma correm o risco de má interpretação da informação, o que pode ocasionar uma precificação errônea. 


\subsection{Efeito lead-lag}

Uma vez que mercados menos desenvolvidos demoram mais tempo pra incorporar as informações no preço de um ativo em relação aos mais desenvolvidos, entende-se que haverá uma defasagem de tempo entre a assimilação da informação nos dois mercados. Essa diferença permite que surja o efeito lead-lag, que Oliveira (2008) define como quando um mercado mais desenvolvido (lead) lidera um mercado menos desenvolvido (lag), criando uma defasagem temporal entre os movimentos de preços. Já Jiang, Fung e Cheng (2001, p. 65) definem o efeito lead-lag de forma mais sucinta, como sendo "o fenômeno que reflete a situação quando dois preços se movem em sequência".

O conceito de efeito lead-lag se relaciona diretamente com os conceitos de arbitragem e HME, uma vez que o fenômeno explicita a reação atrasada de um mercado a determinada informação em relação a outro mercado. O intervalo temporal provocado por esse atraso permitiria a um investidor arbitrar no mercado seguidor, conseguindo auferir ganhos anormais, caso os custos de transação sejam inferiores a esses ganhos. A possibilidade de obtenção de proventos anormais seria uma prova de que a HME nesse contexto é falha, visto que a oportunidade de ganho viria do atraso da incorporação de uma informação no preço do ativo.

\subsubsection{Evidências empíricas sobre o efeito lead-lag}

Diversos estudos já foram realizados com o intuito de testar e comprovar a existência do efeito lead-lag. Tais pesquisas foram feitas buscando provar o fenômeno entre diferentes mercados e entre ações à vista e seus contratos futuros em índices de um mesmo mercado.

Oliveira (2008) testou a existência do efeito lead-lag entre as doze ações mais negociadas na Bovespa e o índice Dow Jones. Por meio de suas análises, descobriu que o retorno da Bovespa é em grande parte explicado pelo movimento da Bolsa de Nova York em minutos anteriores. Descobriu-se que um retorno positivo de $0,02 \%$ na NYSE contribuirá em uma elevação de 19,38\% desse valor na Bovespa um minuto depois. Em seguida, contribuirá com 
11,45\% desse valor e assim sucessivamente até o sétimo minuto seguinte, com percentuais de elevação cada vez menores.

Brooks, Rew e Ritson (2001), por sua vez, analisaram a existência do efeito entre contratos futuros e o índice à vista no mercado acionário de Londres, representado pelo índice FTSE100, utilizando observações com freqüências de 10 minutos. Descobriu-se que retornos futuros conduzem os retornos dos mercados à vista, confirmando sua hipótese de que as informações são primeiramente absorvidas pelo mercado futuro. No entanto, as oportunidades de arbitragem não foram encontradas em virtude dos altos custos de transação, que superavam os retornos anormais.

Na mesma linha de raciocínio, Kawaller, Koch e Koch (1987) testaram a presença do efeito lead-lag entre os índices futuro e à vista do S\&P 500. Da mesma maneira que o estudo anterior, foi percebida uma liderança por parte do índice futuro em relação ao índice à vista, nesse caso em um período de defasagem entre vinte e quarenta e cinco minutos.

Kang, Joo Lee e Lee (2006) testaram a relação lead-lag entre os índices à vista e de futuros da Coréia do Sul, o KOSPI 200. Assim como os outros estudos de mesma natureza, foi descoberto que o índice futuro lidera o à vista em uma defasagem temporal de dez minutos.

Por fim, Kofman e Martens (1997) buscaram examinar a existência do efeito entre os índices futuros de ações das Bolsas de Valores de Londres e Nova York. Foi percebido que o mercado norte-americano liderou o britânico mais que o contrário, apesar de que, em alguns momentos, o mercado britânico chegou a liderar o americano. Em relação às oportunidades de arbitragem e de ganhos anormais, conclui-se que há essa possibilidade caso a operação de compra seja feita imediatamente após a elevação do índice no mercado norte-americano.

\subsection{Revisão metodológica}

\subsubsection{Integração entre o mercado acionário brasileiro e o mercado de ADRs}

Para que o efeito lead-lag entre dois mercados seja possível, a existência de integração entre eles é indispensável, uma vez que, caso não ela não exista, as evidências dessa relação de 
dominância poderão ser consideradas espúrias, ou seja, que são aparentemente significativas, mas que, na verdade, são inexistentes (BROOKS, 2002). No entanto, caso os dois mercados também sejam totalmente integrados, a possibilidade de perceber do efeito lead-lag e de auferir lucros anormais por meio de arbitragem também não existiria, uma vez que, mercados totalmente integrados se movimentam de maneira idêntica, após os ajustes cambiais e tributários. No entanto, é sabido que mercados totalmente integrados não existem na prática (OLIVEIRA, 2008).

Camargos et al. (2003) realizaram um estudo com que buscava não somente comprovar a existência de integração informacional entre os dois mercados, mas também a oportunidade de arbitrar entre eles.

No estudo, o autor separou os dados coletados em quatro variáveis, sendo elas:

- O preço de fechamento diário dos ADRs de empresas brasileiras, negociados na NYSE em dólares (preço efetivo ou $P E A D R_{i, t}$ );

- O preço de fechamento diário das ações brasileiras, correspondentes aos ADRs, negociadas em reais na Bovespa (PrAção $\left.o_{i, t}\right)$;

- Cotação diária do dólar em reais (R\$) por dólar (US\$) (CDólar $\left.{ }_{t}\right)$,

- Número de ações corresponde a cada ADR (NAções).

Para que os testes fossem realizados, o autor decidiu estipular uma nova variável que serviria basicamente para trazer o valor da cotação dos ADRs para a moeda brasileira. Dessa maneira, os valores das ações e das cotações poderiam ser comparados de forma eficaz. A fórmula encontrada pelo autor baseou-se no preço de fechamento em reais de uma ação $i$ no dia $t$ na Bovespa (PrAção $o_{i, t}$ ), na cotação diária do dólar $\left(C D o ́ l a r_{t}\right)$ e no número de ações correspondentes a cada ADR (NAções). A nova variável, que foi denominada de preço teórico do ADR, foi estipulada pela fórmula:

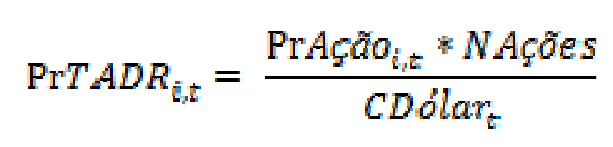

É importante ressaltar que a fórmula do preço teórico do ADR exclui os custos de transação, uma vez que o autor esperava encontrar movimentos iguais para as duas variáveis. Caso ocorresse uma disparidade entre os movimentos dessas variáveis, a HME seria negada, uma vez que possibilidades de arbitragem se tornariam presentes. 
Inicialmente, para que as duas variáveis fossem comparadas, decidiu-se realizar o teste de correlação de Pearson, que mensura a associação linear entre duas variáveis métricas. $\mathrm{O}$ número que representa essa correlação é chamado de coeficiente de correlação, comumente chamado de "r de Pearson". Tal coeficiente pode variar de $-1,00$ a $+1,00$, sendo o zero representando nenhuma relação entre as duas variáveis. Quanto mais próximo de $+1,00$, maior a relação diretamente proporcional das duas variáveis, enquanto, quanto mais próximo de 1,00, maior a relação inversa (HAIR et al., 2005). O cálculo para encontrar o coeficiente de correlação de Pearson é dado por:

$$
r=\frac{\sum_{i=1}^{n}\left(x_{\bar{i}}-\bar{x}\right)\left(y_{i}-\bar{y}\right)}{\sqrt{\sum_{i=1}^{n}\left(x_{i}-\bar{x}\right)^{2}} \cdot \sqrt{\sum_{i=1}^{n}\left(y_{i}-\bar{y}\right)^{2}}}
$$

Em que $x_{1}, x_{2}, \ldots, x_{n}$, e $y_{1}, y_{2}, \ldots, y_{n}$ são os valores medidos de ambas as variáveis.

Matsumoto e Borges (2004) realizaram um estudo com objetivos parecidos aos do autor anterior. Os autores também visaram encontrar evidências de integração entre o mercado brasileiro e o mercado de ADRs e possibilidades de arbitragem entre eles.

Para que uma comparação viável entre as ações e as ADRs pudesse ocorrer, os autores recorreram à metodologia utilizada por Camargos et al. (2003), em que um preço teórico para o ADR é criado tomando como base o valor de fechamento da ação no Brasil e a quantidade de ações que esse recibo representa. Uma vez que as variáveis podiam ser comparadas, os autores, com o intuito de verificar o grau de integração entre os mercados e a possibilidade de arbitragem entre eles, compararam as médias dessas variáveis, realizando o teste $\mathrm{T}$ de Student para duas amostras emparelhadas para médias, com nível de significância de 5\%. As hipóteses testadas foram:

$\mathrm{H}_{0}$ - Não se observa condições de arbitragem, isto é: as médias das duas séries são iguais a $(\bar{X}=0)$

$\mathrm{H}_{1}$ - Existem possibilidades de arbitragem no período, ou seja, as médias das duas séries são diferentes. $(\mathrm{X} \neq 0)$

Para que as médias pudessem ser comparadas, foi utilizado o teste de Correlação de Pearson $r$ de Pearson - como forma de analisar o grau de integração entre as ações e seus respectivos ADRs das empresas pertencentes à amostra. Caso o $r$ de um par de médias seja igual a $+1,00$, 
haverá um confirmação da hipótese $\mathrm{H}_{0}$, significando que há integração total entre os dois papéis, o que reflete em uma conseqüente ausência de efeito lead-lag e a impossibilidade de arbitragem entre os mercados por meio da compra e venda da ação específica.

\subsubsection{Oportunidades de arbitragem entre o mercado brasileiro e o mercado de ADRs}

Carmargos et al. (2003) analisaram em seu estudo não somente o nível de integração entre o mercado acionário brasileiro e o mercado de ADRs, como também verificou a possibilidade de arbitrar entre tais mercados.

Para que tais oportunidades de arbitragem pudessem ser encontradas, os autores decidiram-se por criar uma nova variável denominada "razão" de uma ação $i$ em um dia $t$ em $\mathrm{R} \$$, da seguinte forma:

$$
\operatorname{Raz}_{\mathrm{a} o_{i, t}}=\frac{P T A D R_{i, t}}{P E A D R_{i, t}}
$$

Em que:

$P T A D R_{i, t}=$ Preço teórico da ADR $i$ em um dia $t$

$P E A D R_{i, t}=$ Preço efetivo da ADR $i$ em um dia $t$

Essa variável foi calculada com o intuito de verificar a diferença percentual entre as duas variáveis. Caso $\operatorname{Razão}_{i, t}$ encontrasse um valor igual a 1,10, significaria que o preço teórico da ADR é $10 \%$ superior ao valor do preço efetivo da ADR. Da mesma maneira, caso o valor encontrado fosse 0,80 , significaria que o preço teórico da ADR corresponde a $80 \%$ do preço efetivo.

Desprezando-se os custos de transação e imaginando uma situação perfeita, caracterizada pela ausência de oportunidades de arbitragem, era esperado que a variável $R a z a \tilde{a} o_{i, t}$ fosse igual a um, representando que os mercados se comportam de forma integrada informacionalmente no período. Em compensação, valores muito superiores a um para a razão proposta significaria uma oportunidade de auferir lucros anormais por meio da compra de uma ADR no mercado americano e subsequente venda no mercado brasileiro, enquanto valores muito inferiores a um 
significariam o processo inverso, ou seja, a compra de ações no mercado brasileiro e sua posterior venda no mercado americano.

Para confirmação estatística se a média dessa variável era igual a um, um teste $\mathrm{T}$ para uma amostra com nível de significância de 5\%. A hipótese nula testada seria que a média da variável "razão" era igual a 1.

Por fim, realizou-se o teste Kolmogorov-Smirnov para uma amostra (Analyze Nonparametric Tests - Sample k-S), com o objetivo de avaliar se a diferenças das médias da variável "razão" possuirão distribuição normal, uma vez que, é necessário que os dados apresentem distribuição amostral normal para validação do teste, o que não é exigido no teste T de Student.

\subsubsection{Efeito lead-lag entre os mercados acionários norte-americano e brasileiro}

Para o estudo do efeito lead-lag entre a Bovespa e a NYSE, é necessário realizar uma revisão da metodologia utilizada por Oliveira (2008), cujo escopo do trabalho é exatamente a análise dessa relação entre essas duas bolsas de valores.

\subsubsection{Análise de Regressão}

A pesquisa partiu da hipótese de que há efeitos lead-lag entre as bolsas de valores de Nova York e de São Paulo. Esses efeitos podem ser capturados pela regressão:

$$
p^{i b}{ }_{t}=\beta_{0}+\sum_{i=1}^{n} \beta_{i} P_{t-i}^{i b}+\sum_{j=0}^{n} \gamma_{j} p^{d j-j}+u_{t}
$$

Em que:

$P^{i b}=$ índice de preços das ações listadas na Bolsa de Valores de São Paulo;

$P^{d j}=$ índice de preços das ações listadas na Bolsa de Valores de Nova York;

$\gamma_{i,} \beta_{i}=$ parâmetros a serem estimados na equação; 
$u_{i}=$ erros aleatórios $\sim \mathrm{N}\left(0, \sigma^{2}\right)$.

O autor, no entanto, sugere uma mudança na estrutura da equação, uma vez que ela se utiliza de variáveis não-estacionárias. Brooks (2002) afirma que regressões que se utilizam de variáveis não estacionárias são consideradas regressões espúrias, em que relações aparentemente significativas podem aparecer, mas que, na verdade, são inexistentes. Dessa maneira, o autor sugere utilizar os retornos dos índices de preços das ações, dados por:

$$
R_{t}=\ln \frac{P_{z}}{P_{l-1}}=\Delta \ln P_{t}
$$

O que transforma a primeira equação em:

$$
R^{v}=\beta_{0}+\sum_{i=1}^{n} \beta_{i} R^{u} t-i+\sum_{j=0}^{n} \gamma_{j} R^{a J} t-j+u_{t}
$$

Em que:

$R^{i b}=$ retorno do índice de preços das ações listadas na Bolsa de Valores de São Paulo;

$R^{d j}=$ retorno do índice de preços das ações listadas na Bolsa de Valores de Nova York;

$\gamma_{i,} \beta_{i}=$ parâmetros a serem estimados na equação;

$u_{i}=$ erros aleatórios $\sim \mathrm{N}\left(0, \sigma^{2}\right)$.

No entanto, a presente equação pode apresentar dois problemas econométricos. O primeiro foi identificado como a simultaneidade entre as variáveis $R^{i b}$ e $R^{d j}$, uma vez que existe a chance de não somente $R^{i b}$ ser variável dependente de $R^{d j}$, como a recíproca pode também ser verdadeira, uma vez que $R^{d j}$ é endógena e a nova equação não poderia ser estimada por meio de OLS (Mínimos Quadrados Ordinários). A solução para tal problema seria estimar a equação por um método que leve em conta a simultaneidade dessas variáveis, tais como o TSLS (Two Stage Least Squares), ou Mínimos Quadrados em Dois Estágios, em português. O segundo problema surge, uma vez que existe a possibilidade de que $P^{i b}$ e $P^{d j}$ sejam séries cointegradas. A solução encontrada seria a inserção de um termo de correção de erro, caso seja identificada a existência de co-integração entre os fatores por meio da análise de cointegração. 


\subsubsection{O modelo VECM (Vector Error Correction Model)}

Como forma de verificar em que intensidade os coeficientes dos períodos defasados das séries influenciam uma variação no momento de referência $\left(t_{0}\right)$, o autor se utiliza do modelo de Vetores auto-regressivos, também chamado de VAR. Pelo modelo, o valor de uma variável é expresso como uma função linear de seus valores defasados e das outras variáveis incluídas no modelo. Caso cada equação possuir o mesmo número de variáveis defasadas no sistema, ela poderá ser estimada por Mínimos Quadrados Ordinários, sem que seja necessário recorrer a qualquer método de sistemas, tais como o TSLS.

Dentro do conceito de VAR, também é encontrado o conceito de VECM (Vector Error Correction Model), também conhecido como Vetor de Correção de Erros e que tem como objetivo analisar os ajustamentos de curto prazo que ocorrem nas séries co-integradas (Oliveira, 2008).

Caso os mercados funcionem perfeitamente, seus movimentos de preços devem ser bem descritos pelo VECM de primeira ordem, sendo o termo de correção de erro a diferença de retorno entre os dois mercados.

O modelo VECM será dado por:

$$
\begin{aligned}
& R_{t}^{d j}-R_{t-1}^{d j}=\beta_{1}\left[R_{t-1}^{d j}-R_{t-1}^{i b}\right]+u_{t} \\
& R_{t}^{i b}-R_{t-1}^{i b}=\beta_{2}\left[R_{t-1}^{d j}-R_{t-1}^{i b}\right]+v_{t}
\end{aligned}
$$

Em que:

$R^{i b}=$ retorno do índice de preços das ações listadas na Bolsa de Valores de São Paulo;

$R^{d j}=$ retorno do índice de preços das ações listadas na Bolsa de Valores de Nova York;

$\beta_{1}, \beta_{2}=$ Parâmetros a serem estimados na equação;

$u_{t}$ e $v_{t}=$ os erros aleatórios $\sim \mathrm{N}\left(0, \sigma^{2}\right)$ 


\section{MÉTODOS E TÉCNICAS DE PESQUISA}

\subsection{Tipo e descrição geral da pesquisa}

Método pode ser definido como "etapas dispostas ordenadamente para investigação da verdade, no estudo de uma ciência para atingir determinada finalidade". Técnica, por sua vez, seria fazer de forma mais hábil, segura e perfeita alguma atividade, arte ou ofício. (RIBEIRO DA SILVA, 2003).

A metodologia utilizada nessa pesquisa é descritiva, que Vergara (2000) define como a que expõe as características de determinada população ou fenômeno, estabelece correlações entre suas variáveis e define sua natureza. Além disso, Mattar (1996) afirma que as principais contribuições desse tipo de pesquisa são: "descrever as características dos grupos, estimar a proporção de elementos numa população que tenham determinadas características ou comportamentos e descobrir ou verificar a existência de relação entre as variáveis".

Pesquisas de abordagem quantitativa tem como objetivo medir as relações entre variáveis por associação e obter informações sobre determinada população. Normalmente, suas análises são muito divulgadas, fazendo com que sua planificação necessite de menos explicações que as análises qualitativas (CONTANDRIOPOULOS, 1994).

Portanto, a partir dos enunciados acima descritos, conclui-se que o presente projeto seguirá uma abordagem quantitativa, tendo caráter descritivo e se utilizará de pesquisa documental e bibliográfica para obtenção e análise dos resultados.

\subsection{População e amostra}

A população do presente estudo é compreendida como toda a literatura existente sobre integração de mercados, especialmente no que tange ao mercado brasileiro com o mercado de ADRs, e sobre Efeito lead-lag. 
A amostra foi selecionada por meio de um roteiro, que fornecia os passos para identificação dos pontos principais de cada trabalho científico. Dessa maneira, foram selecionados seis artigos que falam sobre dupla-listagem de ações e integração do mercado acionário brasileiro e o mercado de ADRs, sendo que dois deles foram pesquisados com profundidade, a fim de ser compreendida a metodologia utilizada e os resultados dessa pesquisa. Além disso, foram também selecionados cinco artigos que tratam sobre o efeito lead-lag, no entanto, somente o artigo de Oliveira (2008), que observa a existência do efeito entre o mercado brasileiro e o mercado americano, foi abordado com profundidade, a fim de se entender a metodologia usada e os resultados e conclusões obtidos.

\subsection{Caracterização dos instrumentos de pesquisa}

Por se tratar de uma pesquisa bibliográfica, o estudo se utilizou de diversas fontes de artigos científicos como principais instrumentos de pesquisa. Os sítios da Internet, Web Of Science (http://wok.mimas.ac.uk/); SciELO (http://www.scielo.org/php/index.php), SSRN - Social Science Research Network - (http://www.ssrn.com), e o portal de periódicos CAPES (http://www.periodicos.capes.gov.br/portugues/index.jsp) foram as principais formas de obtenção dos artigos analisados no trabalho. Além disso, o sistema Pergamum ${ }^{\circledR}$, presente no sítio da Internet e nos terminais de pesquisa da Biblioteca Central da Universidade de Brasília (https://consulta.bce.unb.br/pergamum/biblioteca/) foram utilizados como forma de busca de artigos nos assuntos supracitados, por meio de uma pesquisa baseada em palavras-chave.

\subsection{Procedimentos de coleta e de análise de dados}

A coleta de artigos científicos para pesquisa ocorreu entre os dias 09 de Setembro de 2009 e 10 de Novembro de 2009 por meio de pesquisa eletrônica em sítios específicos de artigos científicos e busca presencial de artigos na Biblioteca Central da Universidade de Brasília, por meio do sistema de pesquisa Pergamum ${ }^{\circledR}$. A pesquisa se utilizou de um roteiro para a escolha dos artigos por meio de critérios. Os artigos foram selecionados por critérios de relevância dos 
temas abordados, profundidade com que os assuntos de integração de mercados e efeito leadlag foram discutidos e a data quando foi elaborado, a fim de eliminar artigos desatualizados e fora da realidade em que os mercados estão inseridos. 


\section{RESULTADOS E DISCUSSÃO}

O intuito do presente capítulo é tecer análise acerca dos resultados obtidos pelos teóricos em seus respectivos estudos previamente citados. Dessa maneira, espera-se observar evidências da existência do efeito lead-lag entre o mercado acionário brasileiro e o mercado de ADRs.

\subsection{Estudos sobre a integração de mercados}

\subsubsection{Resultados sobre os testes de correlação de Pearson}

Em seu estudo, Camargos et al. (2003) realizou o teste de correlação de Pearson sobre o valor em reais de fechamento das ações listadas na Bovespa e o valor em dólares de fechamento dos ADRs listados na NYSE.

O período estudado pelo autor compreendeu fevereiro de 1999 e dezembro de 2001, correspondendo a 35 meses e 15.486 observações diárias, sendo uma média de 573 observações por empresa, após os ajustes feitos. O período foi escolhido para evitar que a alteração na política cambial do país, que ocorrera em janeiro de 1999, influenciasse nos resultados da pesquisa.

Para fins de comparação, foi criado um preço teórico da ADR, se utilizando do preço de fechamento da ação em reais, corrigida pela taxa de câmbio do dia e multiplicando-se pela quantidade de ações referente ao ADR da empresa em questão. Dessa maneira, o teste foi aplicado e, descobriu-se que, entre as médias analisadas, todas possuíram um coeficiente de correlação bastante próximo de $+1,00$, ficando entre 0,9571 e 0,9995 (vide Tabela 1). 
Tabela 1 - Correlações do Teste de Correlação de Pearson para duas amostras em par para médias.

\begin{tabular}{|c|c|c|c|c|}
\hline & & $N$ & Correlation & Sig. \\
\hline Ambev & $\mathrm{ABV}-\|^{\mathrm{a}}$ & 672 & ,999 &, 000 \\
\hline Aracruz & ARA - III & 674 & ,995 &, 000 \\
\hline Bradesco & $B B Q C Y-I I$ & 482 &, 979 &, 000 \\
\hline Cemig & CEMCY - II & 528 & ,988 &, 000 \\
\hline Cesp & CESQY - I & 447 &, 957 &, 000 \\
\hline Copel & ELP - II & 674 &, 995 &, 000 \\
\hline Copene & PNE - II & 568 & ,998 &, 000 \\
\hline Eletrobrás & CAIGY - I & 526 & ,990 &, 000 \\
\hline Embraer & ERJ - III & 317 &, 999 &, 000 \\
\hline Embratel & EMT - II & 674 &, 999 &, 000 \\
\hline Gerdau & GGB - II & 529 &, 983 &, 000 \\
\hline Globo Cabo & GLCBY - III & 593 & ,999 &, 000 \\
\hline Pão de Açúcar & CBD - III & 669 &, 999 &, 000 \\
\hline Petrobrás & PBR - I & 303 & ,998 &, 000 \\
\hline $\mathrm{CSN}$ & SID - II & 651 & ,986 &, 000 \\
\hline Tele Cel Sul & TSU - II & 673 &, 998 &, 000 \\
\hline Tele Centro & TRO - II & 671 & ,999 &, 000 \\
\hline Tele Leste Cel & TBE - II & 671 &, 996 &, 000 \\
\hline Tele Nordeste & TND - II & 672 & ,999 &, 000 \\
\hline Tele Norte Cel & $\mathrm{TCN}-\mathrm{II}$ & 673 &, 997 &, 000 \\
\hline Tele Sudeste Cel & TSD - II & 656 & ,997 &, 000 \\
\hline Telemig Cel & TMB - II & 674 & ,999 &, 000 \\
\hline Telesp Part. & TSP - II & 673 & ,995 &, 000 \\
\hline Telesp Cel & TCP - II & 672 &, 999 &, 000 \\
\hline Ultrapar & UGPN - III & 472 &, 993 &, 000 \\
\hline Vale & RIOP - II & 335 & ,996 &, 000 \\
\hline VCP & VCP - III & 381 & ,997 &, 000 \\
\hline
\end{tabular}

${ }^{a} \mathrm{ADR}$ (Código e nível)

Fonte: Camargos et al. (2003)

Com o mesmo embasamento que os Camargos et al., Matsumoto e Borges (2004) estudaram um período mais recente que os autores anteriores. O período estudado pelo autor compreendeu fevereiro de 1999 e dezembro de 2001, correspondendo a 35 meses e 15.486 observações diárias, sendo uma média de 573 observações por empresa, após os ajustes feitos. O período foi escolhido para evitar que a alteração na política cambial do país, que ocorrera em janeiro de 1999, influenciasse nos resultados da pesquisa.

A tabela que segue abaixo apresenta os resultados do teste $T$ aplicado na amostra do estudo. Percebe-se que, em toda amostra, a hipótese $\mathrm{H}_{0}$ foi rejeitada, ou seja, nenhuma empresa apresentou médias entre os preços das ações e ADRs iguais. Apesar de não possuírem médias 
iguais, os coeficientes de correlação de todos os participantes da amostra se mostraram bem próximos de $+1,00$, indicando forte relação entre os mercados.

Tabela 2: Resultados Obtidos com o Teste T; duas amostras em par para médias.

\begin{tabular}{|c|c|c|c|c|c|}
\hline Empresa & $\begin{array}{l}\text { Quant. De } \\
\text { Observações }\end{array}$ & $\begin{array}{l}r \text { (Coeficiente } \\
\text { de Correlação) }\end{array}$ & T - Teste & $\begin{array}{c}\mathrm{T}- \\
\text { Crítico }\end{array}$ & $\begin{array}{c}\text { Rejeitar } \\
\text { Hipótese } \mathrm{H}_{1}\end{array}$ \\
\hline 1 - Ambev & 37 & 0,9907 & $-10,7425$ & 2,0281 & Não \\
\hline 2 - Aracruz & 37 & 0,9966 & $-10,3028$ & 2,0281 & Não \\
\hline 3 - Braskem & 37 & 0,9951 & $-4,1552$ & 2,0281 & Não \\
\hline 4 -Cemig & 29 & 0,9882 & $-6,0083$ & 2,0484 & Não \\
\hline 5 - Copel & 37 & 0,9990 & $-4,1902$ & 2,0281 & Não \\
\hline 6 - Eletrobrás & 37 & 0,9751 & $-6,7184$ & 2,0281 & Não \\
\hline 7 - Embratel Part. & 37 & 0,9999 & $-4,8157$ & 2,0281 & Não \\
\hline 8 - Gerdau & 37 & 0,9967 & $-11,4562$ & 2,0281 & Não \\
\hline 9 - Pão de Açúcar & 37 & 0,9997 & $-6,8586$ & 2,0281 & Não \\
\hline 10 - Petrobras & 37 & 0,9669 & $-9,1133$ & 2,0281 & Não \\
\hline 11 - Sid. Nacional & 37 & 0,9090 & $-4,5820$ & 2,0281 & Não \\
\hline 12 - Tele Cel. Sul & 37 & 0,9992 & $-7,2063$ & 2,0281 & Não \\
\hline 13 - Tele Centroeste & 37 & 0,9892 & $-7,9679$ & 2,0281 & Não \\
\hline 14 - Tele Leste Cel & 37 & 0,9999 & $-4,1589$ & 2,0281 & Não \\
\hline 15 - Tele Nord. Cel & 37 & 0,9954 & $-6,4142$ & 2,0281 & Não \\
\hline 16 - Tele Norte Cel & 37 & 0,9999 & $-2,7303$ & 2,0281 & Não \\
\hline 17 - Tele Sudeste & 37 & 0,9976 & $-6,3783$ & 2,0281 & Não \\
\hline 18 - Telemar & 37 & 0,9925 & $-8,4162$ & 2,0281 & Não \\
\hline 19 - Telemig C Part & 37 & 0,9991 & $-6,6581$ & 2,0281 & Não \\
\hline 20 - Telesp Cel Part & 37 & 0,9999 & $-4,2585$ & 2,0281 & Não \\
\hline 21 - Telesp Operac & 37 & 0,8942 & $-14,4473$ & 2,0281 & Não \\
\hline 22 - Ultrapar & 37 & 0,9087 & $-5,2276$ & 2,0281 & Não \\
\hline 23 - Votorantim CP & 37 & 0,9988 & $-10,4508$ & 2,0281 & Não \\
\hline
\end{tabular}

Fonte: Adaptado de Matsumoto e Borges (2004) 


\subsection{Resultados sobre os testes de oportunidade de arbitragem}

O teste realizado por Camargos et al. (2003) utilizou-se de uma razão entre o preço teórico e o preço efetivo de uma ADR a fim de perceber as diferenças percentuais entre as variáveis. Para que pudesse ser confirmado estatisticamente que a média dessa nova variável era igual a um, realizou-se um teste T para uma amostra com significância de 5\%, cujos resultados aparecem na tabela a seguir.

Tabela 3: Teste T para uma amostra (One-Sample)

\begin{tabular}{|c|c|c|c|c|c|c|}
\hline & \multicolumn{6}{|c|}{ Test Value $=1$} \\
\hline & \multirow[b]{2}{*}{$t$} & \multirow[b]{2}{*}{$d f$} & \multirow{2}{*}{$\begin{array}{c}\text { Sig. } \\
\text { (2-tailed) }\end{array}$} & \multirow{2}{*}{$\begin{array}{c}\text { Mean } \\
\text { Difference }\end{array}$} & \multicolumn{2}{|c|}{$\begin{array}{c}95 \% \text { Confidence } \\
\text { Interval of the } \\
\text { Difference }\end{array}$} \\
\hline & & & & & Lower & Upper \\
\hline Amber &, 625 & 676 &, 532 & $2,361 E-02$ & $-5,05 \mathrm{E}-02$ & $9,773 \mathrm{E}-02$ \\
\hline Aracruz &, 789 & 678 &, 431 & $2,920 E-02$ & $-4,35 \mathrm{E}-02$ &, 1019 \\
\hline Bradesco & 5,141 & 481 &, $000^{\mathrm{a}}$ & $1,127 \mathrm{E}-02$ & $6,960 \mathrm{E}-03$ & $1,557 \mathrm{E}-02$ \\
\hline Cemig & 3,425 & 527 & ,001 & $6,407 E-03$ & $2,732 \mathrm{E}-03$ & $1,008 \mathrm{E}-02$ \\
\hline Cesp & 7,588 & 446 &, 000 & $4,771 \mathrm{E}-02$ & $3,536 \mathrm{E}-02$ & $6,007 \mathrm{E}-02$ \\
\hline Copel & $-2,773$ & 673 & ,006 & $-1,817 \mathrm{E}-03$ & $-3,10 \mathrm{E}-03$ & $-5,30 \mathrm{E}-04$ \\
\hline Copene & ,911 & 572 &, 363 & $3,639 \mathrm{E}-02$ & $-4,21 \mathrm{E}-02$ &, 1148 \\
\hline Eletrobrás & 4,095 & 525 &, 000 & $5,869 \mathrm{E}-03$ & $3,054 \mathrm{E}-03$ & $8,685 \mathrm{E}-03$ \\
\hline Embraer &, 251 & 316 &, 802 & $1,770 E-04$ & $-1,21 \mathrm{E}-03$ & $1,567 \mathrm{E}-03$ \\
\hline Embratel & 1,199 & 675 &, 231 & $8,199 \mathrm{E}-04$ & $-5,23 E-04$ & $2,163 \mathrm{E}-03$ \\
\hline Gerdau & $-2,334$ & 528 &, 020 & $-5,430 \mathrm{E}-03$ & $-1,00 \mathrm{E}-02$ & $-8,60 \mathrm{E}-04$ \\
\hline Globo Cabo & 1,468 & 592 &, 143 & $1,618 \mathrm{E}-03$ & $-5,46 \mathrm{E}-04$ & $3,782 \mathrm{E}-03$ \\
\hline Pão de Açúcar & 4,935 & 668 &, 000 & $2,884 \mathrm{E}-03$ & $1,737 \mathrm{E}-03$ & $4,032 E-03$ \\
\hline Petrobrás & ,336 & 307 &, 737 & $1,968 \mathrm{E}-02$ & $-9,56 \mathrm{E}-02$ &, 1350 \\
\hline $\mathrm{CSN}$ & $-3,587$ & 650 &, 000 & $-6,403 E-03$ & $-9,91 \mathrm{E}-03$ & $-2,90 \mathrm{E}-03$ \\
\hline TCsul & 2,512 & 672 & ,012 & $2,007 \mathrm{E}-03$ & $4,384 \mathrm{E}-04$ & $3,576 \mathrm{E}-03$ \\
\hline TCoest & 1,609 & 670 &, 108 & $1,580 E-03$ & $-3,48 \mathrm{E}-04$ & $3,508 \mathrm{E}-03$ \\
\hline TLeste & 4,838 & 670 &, 000 & $4,212 \mathrm{E}-03$ & $2,503 E-03$ & $5,921 \mathrm{E}-03$ \\
\hline TNordes & 3,661 & 671 &, 000 & $3,129 \mathrm{E}-03$ & $1,451 \mathrm{E}-03$ & $4,807 \mathrm{E}-03$ \\
\hline TSudeste & 2,220 & 655 &, 027 & $2,845 E-03$ & $3,286 \mathrm{E}-04$ & $5,361 \mathrm{E}-03$ \\
\hline TNorte &,- 257 & 671 &, 797 & $-2,267 \mathrm{E}-04$ & $-1,96 \mathrm{E}-03$ & $1,505 \mathrm{E}-03$ \\
\hline Telemig Cel &, 934 & 673 & ,351 & $6,903 E-04$ & $-7,61 \mathrm{E}-04$ & $2,141 \mathrm{E}-03$ \\
\hline Telesp part &,- 803 & 672 &, 422 & $-1,013 \mathrm{E}-03$ & $-3,49 \mathrm{E}-03$ & $1,463 \mathrm{E}-03$ \\
\hline Telesp cel & $-6,924$ & 671 &, 000 & $-4,830$ E- 03 & $-6,20 \mathrm{E}-03$ & $-3,46 \mathrm{E}-03$ \\
\hline Ultrapar & 9,519 & 471 &, 000 & $1,069 \mathrm{E}-02$ & $8,480 \mathrm{E}-03$ & $1,289 \mathrm{E}-02$ \\
\hline Vale & $-4,382$ & 337 &, 000 & $-2,423 \mathrm{E}-03$ & $-3,51 \mathrm{E}-03$ & $-1,34 \mathrm{E}-03$ \\
\hline VCP & 2,055 & 382 & ,041 & $1,501 \mathrm{E}-03$ & $6,502 \mathrm{E}-05$ & $2,936 \mathrm{E}-03$ \\
\hline
\end{tabular}

a. Valores que rejeitaram $\mathrm{H}_{0}$ (em negrito)

Fonte: Camargos et al. (2003) 
Na tabela 3, é possível perceber que das 27 empresas da amostra utilizada, 16 rejeitaram a hipótese nula, corroborando-se a idéia de que, para grande parte da amostra, há suspeitas de oportunidades de arbitragem no período.

Em seguida, foi realizado o teste de Kolmogorov-Smirnov com o objetivo de verificar se o teste realizado seria válido, uma vez que, para que isso aconteça, seria necessário que o teste possuísse uma distribuição amostral normal. Os resultados podem ser vistos na tabela 4.

Tabela 4: Teste Kolmogorov-Smirnov para diferenças médias

\begin{tabular}{llr}
\hline & & \multicolumn{1}{c}{ Médias } \\
\hline $\mathrm{N}$ & & 27 \\
Normal Parameters ${ }^{a, b}$ & Mean & $-7,06 \mathrm{E}-04$ \\
& Std. Deviation & $8,023 \mathrm{E}-02$ \\
Most Extreme Differences & Absolute &, 117 \\
& Positive &, 117 \\
Kolmogorov-Smirnov Z & Negative &,- 075 \\
& &, 607 \\
Asymp. Sig. (2-tailed) & &, 855 \\
\hline
\end{tabular}

a. Test distribution is Normal.

b. Calculated from data.

Fonte: Camargos et al. (2003)

O resultado do teste acima valida o teste acima, uma vez que fora comprovado que a diferenças das médias da variável razão tem distribuição normal.

\subsection{Efeito lead-lag entre o mercado acionário brasileiro e norte-americano}

Oliveira (2008) delimitou em seu estudo dois modelos para verificar a correlação e a intensidade com que coeficientes de períodos defasados das duas séries - ações da Ibovespa e Dow Jones - influenciam no momento $t_{0}$ do índice Ibovespa. Tais modelos foram a Regressão 
Linear estimada por TSLS (Mínimos Quadrados em Dois Estágios) e o modelo Vetor AutoRegressivo com .correção de erro (VECM)

\subsubsection{Resultados do modelo TSLS}

Em primeiro lugar, o autor realizou seus testes utilizando-se do modelo de regressão linear proposto no sub-item 2.6.2.1, do capítulo "Referencial Teórico", considerando a variável $R^{d j}$ como exógena, o que não necessitaria da utilização dos Mínimos Quadrados em Dois Estágios para correção.

A tabela abaixo demonstra os coeficientes de correlação distribuídos entre as defasagens temporais em uma regressão em que $R^{d j}$ é a variável dependente. Percebe-se que a série Ibovespa é significativa, mesmo que de forma fraca, quando utilizado dummy para retornos positivos e utilizando-se de uma significância estatística de 5\%.

Tabela 5: Regressão OLS das variáveis $R^{i b}$ e $R^{d j}$ (dependente) com dummy para retornos positivos

\begin{tabular}{lrrrr}
\hline \multicolumn{1}{c}{ Variable } & Coefficient & Std. Error & t-Statistic & Prob. \\
\hline C & $7,71 \mathrm{E}-06$ & $7,08 \mathrm{E}-07$ & 10,88269 & 0,000000 \\
DLOG(DI(-1)) & 0,004417 & 0,002063 & 2,140630 & 0,032300 \\
DLOG(DJ(-2)) & $-0,010404$ & 0,002078 & $-5,006047$ & 0,000000 \\
DLOG(DJ(-3)) & $-0,008022$ & 0,002081 & $-3,855710$ & 0,000100 \\
DLOG(DJ(-4)) & $-0,009918$ & 0,002077 & $-4,776043$ & 0,000000 \\
DLOG(IBOV) & 0,011604 & 0,001086 & 10,68425 & 0,000000 \\
DLOG(IBOV(-1)) & 0,014103 & 0,001126 & 12,52486 & 0,000000 \\
DLOG(IBOV(-2)) & 0,007130 & 0,001125 & 6,337884 & 0,000000 \\
DLOG(IBOV(-3)) & 0,003526 & 0,001117 & 3,157902 & 0,001600 \\
DLOG(IBOV(-4)) & 0,004800 & 0,001093 & 4,392987 & 0,000000 \\
\hline & & & & \\
\hline R-squared & 0,003958 & Mean dependent var & $7.86 \mathrm{E}-06$ \\
Adjusted R-squared & 0,003873 & S.D. dependent var & 0,00023 \\
S.E. of regression & 0,00023 & Akaike info criterion & $-13,91801$ \\
Sum squared resid & 0,005571 & Schwarz criterion & $-13,91710$ \\
Log likelihood & 733753,7 & F-statistic & 46,54395 \\
Durbin-Watson stat & 2,012031 & Prob(F-statistic) & 0,00000 \\
\hline
\end{tabular}

Fonte: Oliveira (2008) 
A tabela seguinte apresenta as mesmas condições do teste anterior, utilizando, no entanto, dummy para retornos negativos. Nesse caso, a variável $R^{i b}$, em sua defasagem de quatro minutos, não apresentou significância estatística de 5\%.

Tabela 6: Regressão OLS das variáveis $R^{i b}$ e $R^{d j}$ (dependente) com dummy para retornos negativos

\begin{tabular}{lrrrr}
\hline \multicolumn{1}{c}{ Variable } & Coefficient & Std. Error & t-Statistic & Prob. \\
\hline C & $-3,21 E-05$ & $6,61 E-07$ & $-48,59469$ & 0,00000 \\
DLOG(DJ(-1)) & 0,008849 & 0,001927 & 4,592801 & 0,00000 \\
DLOG(DJ(-2)) & $-0,004084$ & 0,001941 & $-2,104309$ & 0,03540 \\
DLOG(DJ(-3)) & $-0,002276$ & 0,001943 & $-1,171414$ & 0,24140 \\
DLOG(DJ(-4)) & $-0,002620$ & 0,001939 & $-1,351224$ & 0,17660 \\
DLOG(IBOV) & 0,011994 & 0,001014 & 11,82640 & 0,00000 \\
DLOG(IBOV(-1)) & 0,013078 & 0,001051 & 12,43855 & 0,00000 \\
DLOG(IBOV(-2)) & 0,004216 & 0,001051 & 4,013318 & 0,00010 \\
DLOG(IBOV(-3)) & 0,002336 & 0,001043 & 2,239933 & 0,02510 \\
DLOG(IBOV(-4)) & $-0,000209$ & 0,001020 & $-0,204878$ & 0,83770 \\
& & & & \\
\hline R-squared & 0,004335 & Mean dependent var & $-3,20 E-05$ \\
Adjusted R-squared & 0,00425 & S.D. dependent var & 0,000215 \\
S.E. of regression & 0,000215 & Akaike info criterion & $-14,05503$ \\
Sum squared resid & 0,004858 & Schwarz criterion & $-14,05412$ \\
Log likelihood & 740969,9 & F-statistic & 50,99688 \\
Durbin-Watson stat & 1938121 & Prob(F-statistic) & 0,00000 \\
\hline
\end{tabular}

Fonte: Oliveira (2008)

Dessa maneira, o autor concluiu que os resultados de tais regressões indicaram que a série Dow Jones é endógena, acarretando em simultaneidade na regressão, o que obriga a realizar o teste se utilizando do método TSLS, a fim de que uma análise mais realista seja elaborada.

\subsubsection{Coeficientes significativos para retornos positivos}

Utilizando-se da regressão pelo método TSLS e com dummy de retorno positivo, descobriu-se uma grande influência dos períodos defasados da série Dow Jones nos movimentos da Ibovespa, em um teste em que o nível de significância exigido foi de 5\%. 
Tabela 7: Regressão TSLS das variáveis $R^{i b}$ (dependente) e $R^{d j}$ com $d u m m y$ para retornos positivos

\begin{tabular}{crrrr}
\hline Variable & Coefficient & Std, Error & t-Statistic & Prob. \\
\hline C & 0,000149 & $8,64 E-07$ & 172,8133 & 0 \\
DLOG(IBOV(-1)) & $-0,000484$ & 0,001377 & $-0,351568$ & 0,7252 \\
DLOG(IBOV(-2)) & $-0,007845$ & 0,001377 & $-5,698065$ & 0 \\
DLOG(IBOV(-3)) & $-0,007536$ & 0,001377 & $-5,472939$ & 0 \\
DLOG(IBOV(-4)) & $-0,002102$ & 0,001377 & $-1,526518$ & 0,1269 \\
DLOG(DJ) & 0,037001 & 0,002383 & 15,5286 & 0 \\
DLOG(DJ(-1)) & 0,193812 & 0,002472 & 78,41562 & 0 \\
DLOG(DJ(-2)) & 0,114543 & 0,002521 & 45,43227 & 0 \\
DLOG(DJ(-3)) & 0,050621 & 0,00254 & 19,92839 & 0 \\
DLOG(DJ(-4)) & 0,024446 & 0,002543 & 9,614649 & 0 \\
DLOG(DJ(-5)) & 0,013615 & 0,002457 & 5,542427 & 0 \\
DLOG(DJ(-6)) & 0,009642 & 0,002406 & 4,008208 & 0,0001 \\
DLOG(DJ(-7)) & 0,009991 & 0,002386 & 4,186484 & 0 \\
DLOG(DJ(-8)) & 0,002969 & 0,002382 & 1,246399 & 0,2126 \\
DLOG(DJ(-9)) & $-0,002996$ & 0,002381 & $-1,258213$ & 0,2083 \\
DLOG(DJ(-10)) & $-0,003171$ & 0,00238 & $-1,332615$ & 0,1827 \\
\hline
\end{tabular}

Fonte: Oliveira (2008)

Somente a partir do oitavo minuto de defasagem que os coeficientes da série Dow Jones deixam de ter significância estatística. Antes disso, todos os coeficientes significativos das variáveis defasadas do índice da bolsa americana foram positivos.

Percebe-se que a correlação positiva existente entre o índice da bolsa norte-americana e o índice da brasileira tem seu pico logo no primeiro minuto que antecede o momento $t_{0}$, reduzindo progressivamente em seguida, como é possível ser visto no gráfico abaixo. 


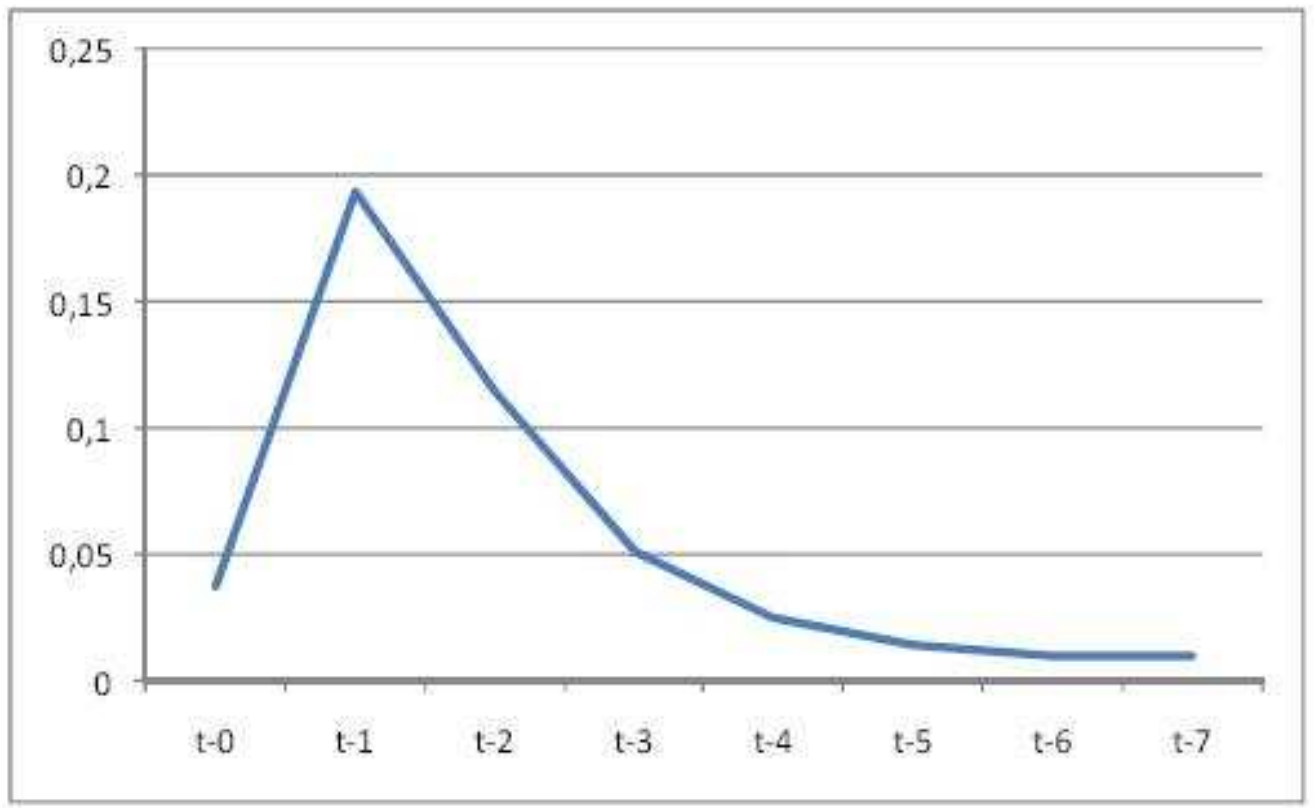

Gráfico 2: Coeficientes dos lags do índice Dow Jones - TSLS, retornos positivos

Fonte: Oliveira (2008)

A soma de todos os coeficientes no teste realizado é de 0,453671 . Tal valor indica que o momento atual da Bolsa de Valores de Nova York e seus sete minutos que o antecedem, explicam 45,37\% do retorno da Bolsa de Valores de São Paulo no momento atual, o que explicaria quase metade de seu movimento. Tal verificação pode ser observada no gráfico abaixo, que apresenta os coeficientes acumulados. 


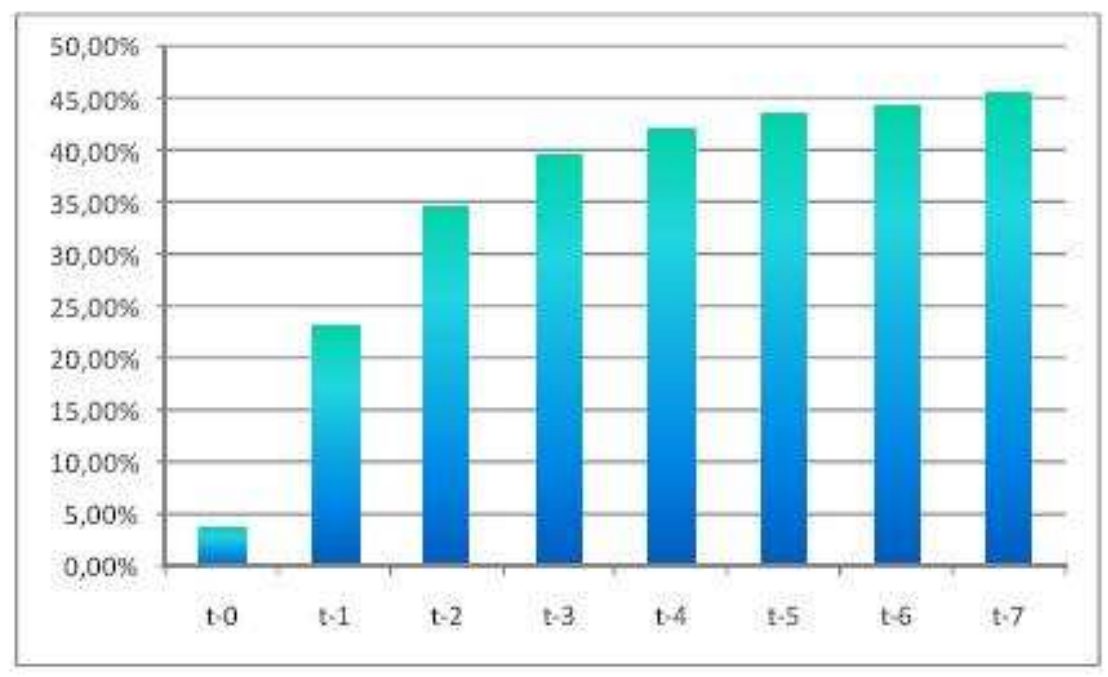

Gráfico 3: Coeficientes acumulados dos lags do índice Dow Jones - TSLS, retornos positivos

Fonte: Oliveira (2008)

\subsubsection{Coeficientes significativos para retornos negativos}

As mesmas condições aplicadas ao teste anterior foram aplicadas ao que será apresentado, no entando, um dummy para retornos negativos será utilizado.

Tabela 8: Regressão TSLS das variáveis $R^{i b}$ (dependente) e $R^{d j}$ com dummy para retornos negativos

\begin{tabular}{crrrr}
\hline Variable & Coefficient & Std, Error & t-Statistic & Prob. \\
\hline C & $-2,64 \mathrm{E}-05$ & $9,78 \mathrm{E}-07$ & $-26,96551$ & 0 \\
DLOG(IBOV(-1)) & 0,005501 & 0,001559 & 3,529149 & 0,0004 \\
DLOG(IBOV(-2)) & $-0,001928$ & 0,001559 & $-1,237119$ & 0,216 \\
DLOG(IBOV(-3)) & $-0,00173$ & 0,001559 & $-1,109718$ & 0,2671 \\
DLOG(IBOV(-4)) & 0,004351 & 0,001559 & 2,790832 & 0,0053 \\
DLOG(DJ) & 0,042383 & 0,002698 & 15,71064 & 0 \\
DLOG(DJ(-1)) & 0,172321 & 0,002798 & 61,58221 & 0 \\
DLOG(DJ(-2)) & 0,107115 & 0,002854 & 37,5268 & 0 \\
DLOG(DJ(-3)) & 0,060432 & 0,002876 & 21,0136 & 0 \\
DLOG(DJ(-4)) & 0,019266 & 0,002879 & 6,693029 & 0 \\
DLOG(DJ(-5)) & 0,017923 & 0,002781 & 6,444348 & 0 \\
DLOG(DJ(-6)) & 0,005979 & 0,002723 & 2,195263 & 0,0281 \\
DLOG(DJ(-7)) & 0,013378 & 0,002702 & 4,951372 & 0 \\
DLOG(DJ(-8)) & 0,012126 & 0,002697 & 4,496686 & 0 \\
DLOG(DJ(-9)) & 0,004597 & 0,002696 & 1,705191 & 0,0882 \\
DLOG(DJ(-10)) & 0,006779 & 0,002694 & 2,516146 & 0,0119 \\
\hline
\end{tabular}

Fonte: Oliveira (2008) 
As variáveis de defasagens de dois e três minutos da Bovespa, assim como a variável de defasagem de nove minutos do índice Dow Jones foram os únicos que não alcançaram o nível proposto de significância.

O momento atual e os oito minutos antecedentes apresentaram significância nos movimentos do Ibovespa no momento atual, sendo o primeiro minuto de defasagem o principal deles, uma vez que $17,23 \%$ de um retorno negativo ocorrido no Ibovespa pode ser explicado pelo movimento do Dow Jones um minuto antes.

O gráfico elaborado com os coeficientes para retornos negativos se assemelhou bastante ao mesmo para retornos positivos, tendo o coeficiente referente à defasagem do primeiro minuto a de maior valor absoluto, conforme é possível verificar abaixo:

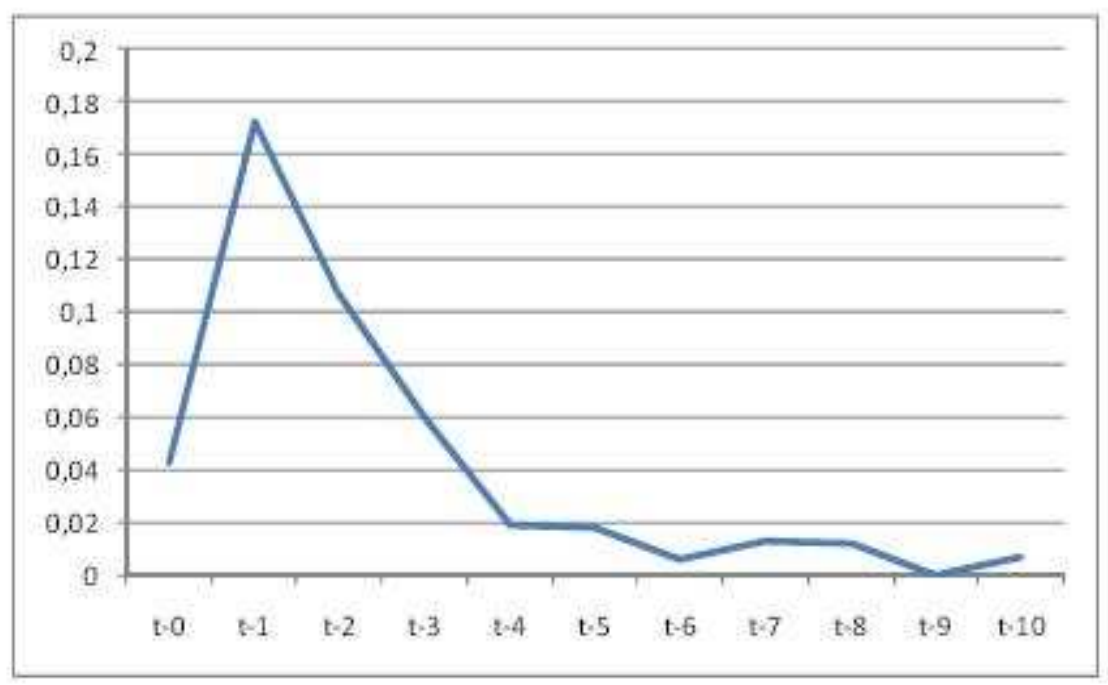

Gráfico 4: Coeficientes dos lags do índice Dow Jones - TSLS, retornos negativos

Fonte: Oliveira (2008)

É possível perceber também que a soma de todos os coeficientes é de 0,457702, valor esse muito semelhante o encontrado no teste com retornos positivos. Tal valor sugere que o retorno negativo do momento atual da Bolsa de Nova York e os oito minutos que o antecedem explicam 45,77\% do retorno da bolsa de São Paulo no momento atual, como é possível perceber abaixo no gráfico de coeficientes acumulados. 


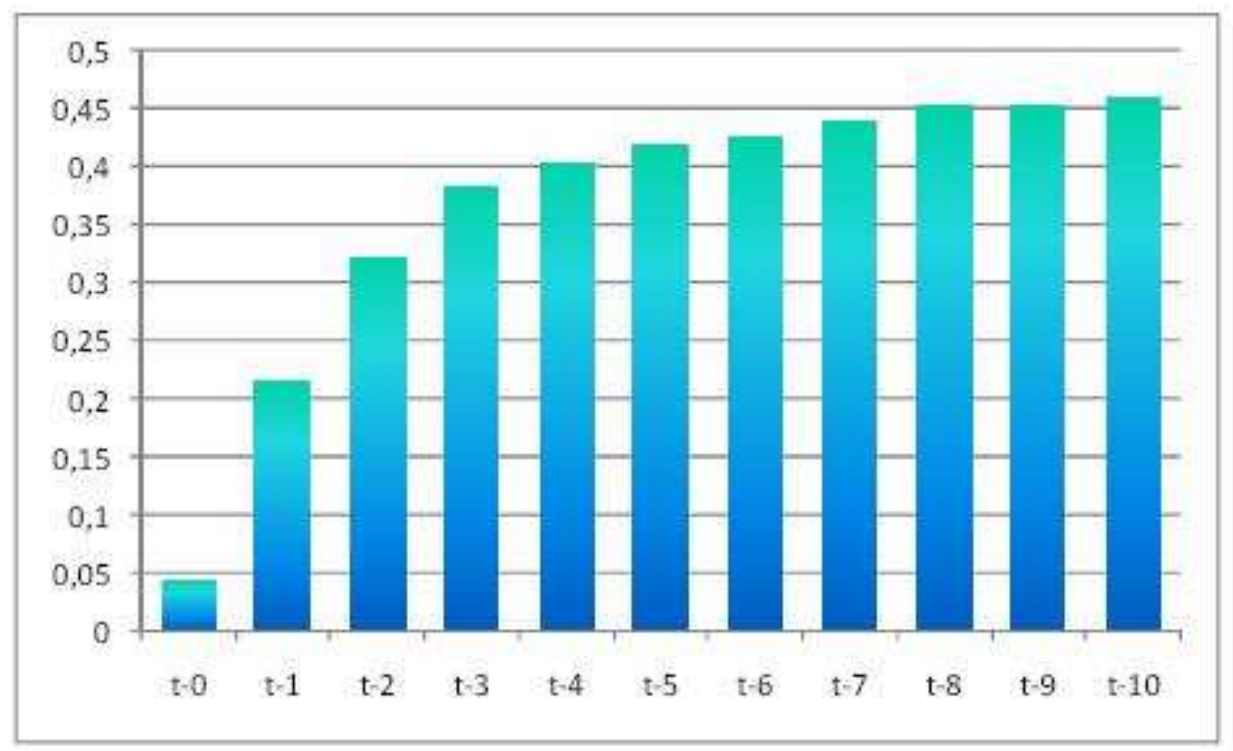

Gráfico 5: Coeficientes acumulados dos lags do índice Dow Jones - TSLS, retornos negativos Fonte: Oliveira (2008)

\subsubsection{Resultados do modelo VECM}

Além do modelo TSLS, o autor também se utilizou dos Modelos de Vetores AutoRegressivos a fim de confirmar o nível de dependência do índice Ibovespa aos valores antecedentes das duas variáveis $\left(R^{i b}\right.$ e $\left.R^{d j}\right)$. Por definição, no longo prazo, as variáveis convergem para um mesmo valor e não se alteram mais, tornando a diferença entre elas igual a zero (BROOKS, 2002 apud OLIVEIRA, 2008). Para que tal erro fosse eliminado, o autor se utilizou do VECM (Vector Error Correctio Model) para verificar a relação entre os valores prévios das variáveis com o valor atual do Ibovespa. A variável câmbio foi excluída do estudo, uma vez que, após alguns testes, essa se mostrou pouco influente na variação do índice da Bolsa de São Paulo.

No estudo em que o Modelo VECM foi utilizado, o tempo de influência da variável Dow Jones identificado foi de dez minutos. Para os períodos de $t$ - 1 a $t$-10, todos os coeficientes encontrados foram significativos e positivos, sendo o maior no momento $t$ - 1 , equivalente a 0,367950, e o menor no momento $t-9$, cujo coeficiente foi de 0,013374 . Da mesma maneira que no estudo realizado utilizando-se o modelo TSLS, o coeficiente encontrado representa em 
que proporção cada movimento, em instantes anteriores na NYSE, reflete no nível do Ibovespa. O gráfico abaixo representa os coeficientes da variável em cada lag.

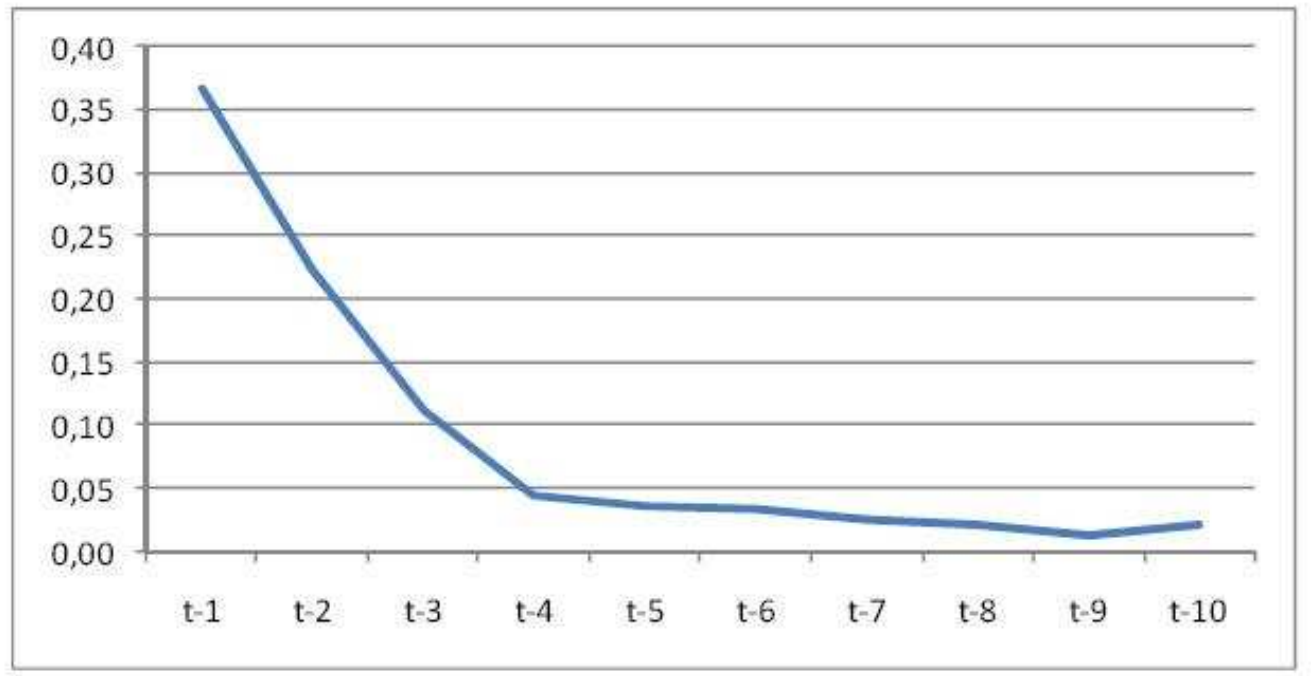

Gráfico 5: Coeficientes acumulados dos lags do índice Dow Jones - TSLS, retornos negativos

Fonte: Oliveira (2008)

Percebe-se pelo gráfico que os três primeiros minutos que antecedem a variação do Ibovespa são cruciais para a assimilação da informação pelo valor do ativo, enquanto os sete minutos restantes e mais distantes exercem uma influência menor. 


\section{CONCLUSÃO E RECOMENDAÇÕES}

Esse trabalho buscou analisar se a literatura científica existente é capaz de apontar para a existência do efeito lead-lag entre o mercado acionário brasileiro, aqui representado pela Bovespa, e o mercado de recibos depositários do mercado norte-americano, ou simplesmente, ADR. Para isso, foi realizada a revisão metodológica de diversos artigos científicos na área, com o objetivo de identificar pontos em comum entre eles que pudessem levar à dedução da existência da relação.

Em primeiro lugar, foram verificados os estudos de Camargos et al. (2003) e Matsumoto e Borges (2004), uma vez que esses tiveram o objetivo de verificar a o grau de integração entre os mercados que são foco do presente estudo. Concluiu-se que os dois mercados são altamente integrados, tendo os coeficientes de correlação das empresas utilizadas nas amostras bem próximos de $+1,00$, que representaria total integração informacional, retirandose os custos transacionais. Além disso, um coeficiente de correlação igual a $+1,00$ comprovaria a HME, que afirma que as informações do mercado são absorvidas instantaneamente e que possibilidades de auferir lucros anormais por meio de arbitragem seriam inexistentes. Apesar de os coeficientes estarem bem próximos do valor correspondente à integração total, tal fato não impede que oportunidades de arbitragem entre os mercados existam.

Uma vez identificado a alta correlação entre os mercados, com valores, porém, que não excluíam as possibilidades de arbitragem, Camargos et al.(2003) criou uma nova variável denominada razão para identificar a diferença percentual entre o preço teórico da ADR, calculado a partir do valor de fechamento das ações no mercado brasileiro, e o preço efetivo da ADR. Por meio dessa análise, descobriu-se que mais da metade da amostra rejeitava a hipótese de que o valor da razão proposta seria igual a 1, o que comprovaria que os mercados se movimentam de forma integrada e sem defasagens temporais.

Em seguida, foi explorado o trabalho científico de Oliveira (2008), que tratou de analisar o efeito lead-lag entre a bolsa de valores de São Paulo e de Nova York. Fora concluído, pelos dois modelos propostos para tal - Análise de Regressão com Mínimos Quadrados de Dois 
Estágios e Modelo VECM - que os retornos da bolsa de valores de São Paulo, tanto positivos quanto os negativos, são explicados em parte pelos movimentos da bolsa de valores de Nova York no momento e nos minutos que antecedem o tal variação. Dessa maneira, uma relação de dominância da NYSE em relação à Bovespa poderia ser identificada, uma vez que as variações da bolsa estadunidense influenciariam diretamente nas movimentações do mercado brasileiro minutos depois, criando oportunidades claras de arbitragem e de previsão de movimentos do mercado, provando que a variação de preços no mercado acionário não é um processo estocástico, como proposto pela HME.

A revisão das literaturas, portanto, suscita deduções sobre a existência do efeito lead-lag entre as ações da Bovespa e seus ADRs. Em primeiro lugar, a literatura sobre a integração dos mercados brasileiro e de ADRs comprovou a existência de oportunidades de arbitragem entre eles. No entanto, por se mostrarem altamente correlacionados, muitos estudos apontaram para uma correção no preço do mercado defasado minutos depois. Uma vez que ambos os mercados são altamente correlacionados, mas não se movimentam de forma conjunta, ou seja, apresentam defasagens temporais entre seus movimentos, surgiria uma evidência de existência do efeito lead-lag entre tais mercados, uma vez que o mercado defasado se tornaria previsível.

No entanto, por causa do alto grau de correlação identificado entre as ações da Bovespa e seus recibos depositários na NYSE, pressupõe-se que o mercado defasado em questão seria o de ADRs, uma vez que tais papéis representam as ações no mercado brasileiro, fonte das informações relevantes a precificação das ações. Além disso, é pressuposto também que o período de antecedência identificado como o que explica o preço no mercado defasado em um momento $t_{0}$ será menor que aquele visto por Oliveira (2008), assim como a soma dos coeficientes significativos provavelmente será maior. Tal fato poderia ser explicado pelo fato de ser muito alto o grau de correlação entre os papéis desses mercados.

Em compensação, mesmo no estudo proposto por Oliveira (2008), a possibilidade de auferir lucros anormais fica comprometida em virtude dos custos transacionais entre os mercados, que acabam superando os lucros obtidos por meio da utilização dessa estratégia. Essa inviabilização, no caso do estudo entre os mercados brasileiro e norte-americano, se dá em virtude da baixa variação encontrada dentro do período proposto pelo autor, que seria de aproximadamente sete a oito minutos antes, que seria capaz de trazer retornos muito pequenos, que não seriam suficientes para cobrir os custos de transação e ainda gerar lucro. 
Tal característica é encontrada da mesma maneira nos trabalhos científicos que tratam sobre as oportunidades de arbitragem entre a Bovespa e os ADRs. Por causa do lapso temporal muito curto e por causa da baixa variação no preço dentro desse período, a realização de arbitragem entre os mercados ficaria inviabilizada por causa dos custos de transação, maiores que os retornos previstos.

Ainda que os trabalhos existentes na área sobre efeito lead-lag entre os mercados brasileiro e norte-americano e integração de ações duplamente listadas apontem evidências para a existência do efeito entre ambos os mercados, a necessidade de uma comprovação do efeito por meio de um estudo empírico se faz presente, tornando-se esse uma proposta para futuros estudos na área. 


\section{REFERÊNCIAS}

ANDREZO, A. F.; LIMA, I. S. Mercado Financeiro: Aspectos Históricos e Conceituais. São Paulo: Pioneira, 1999.

ASSAF NETO, A. Mercado Financeiro. 8ª Ed. São Paulo: Atlas, 2009.

ASSAF NETO, A.; LIMA, F. G.; DE ARAÚJO, A. M. P. A realidade da concentração do capital no Brasil: Um estudo comparativo com duas outras economias emergentes. Disponível em $<$ http://www.institutoassaf.com.br/downloads/artigo_concentracao

do_capital_no_brasil.pdf>. Acessado em 24 de Setembro de 2009. 2007.

BARBETTA, P. A. Estatística Aplicada às Ciências Sociais. $6^{a}$ Ed. Florianópolis: Editora da UFSC, 2006.

BERNSTEIN, P. L. Capital Ideas. 2a Ed. Nova York: John Wiley and Sons, 2007.

BOVESPA - Disponível em <www.bovespa.com.br>. Acesso em 15 de Setembro de 2009.

BROOKS, C. Introductory Econometrics for Finance. $1^{\text {a }}$ Ed. Cambridge: Cambridge University Press, 2002.

; REW, A. G.; RITSON, S. A Trading Strategy Based on The Lead-Lag Relationship Between the Spot Index and Futures Contract for the FTSE-100. International Journal of Forecasting. v. 17, 2001.

BRUNI, A. L.; FAMÁ, R. Uma Análise da Eficiência Informacional do Mercado de ADRs Brasileiros com Base em Testes de Autocorrelação, Raiz Unitária e Co-integração. Anais do XXVII Encontro Anual da Associação Nacional dos Programas de Pós-Graduação em Administração (ENANPAD 2003). ANPAD, Atibaia, Brasil, 20-24/09/2003.

CAMARGOS, M. A.; GOMES, G. D.; BARBOSA, F. V. Integração de Mercados e Arbitragem com Títulos Transfronteiriços: ADRs - American Depositary Receipts. Caderno de Pesquisas em Administração. São Paulo, v. 10, n. 2, p. 51-67, abril/junho 2003.

CONTANDRIOPOUlOS, A. P.; CHAMPAGNE, F.; POTVIN, L.; DENIS, J. L.; BOYLE, P. Saber Preparar uma Pesquisa. 1994. São Paulo: Hucitec/Rio de Janeiro: Abrasco. 
COSTA JUNIOR, N. C. A.; LEAL, R. P. C. A Integração entre as Bolsas de Valores de Buenos Aires e de São Paulo. Revista de Administração Contemporânea, vol. 2. 1998.

COSTA JUNIOR, N. C. A.; LEAL, R. P. C. Mercosul e a Globalização dos Mercados de Capitais: Testes de Casualidade. Revista de Administração, v. 32, 1997.

DE MEDEIROS, O. R.; LIMA, M. E. Brazilian Dual-Listed Stocks, Arbitrage and Barriers. 2006. Disponível em SSRN: http://ssrn.com/abstract=896358.

GROPPO, G. S.; BACCHI, M. R. P. Casualidade entre Mercados Acionários: Estudo sobre Ibovespa, Dow Jones e Merval. Resenha BM\&F. n. 166. 2005.

HAIR, J. F.; BABIN, B.; MONEY, A.; SAMOUEL, P. Fundamentos de Métodos de Pesquisa em Administração. $7^{\text {a }}$ Ed. Porto Alegre: Bookman, 2003.

JIANG, L.; FUNG, J. K. W.; CHENG, L. T. W. The Lead-Lag Relation Between Spot and Futures Markets Under Different Short-Selling Regimes. The Financial Review. n. 38, p. 63$88,2001$.

KANG, J.; JOO LEE, C.; LEE, S. An Empirical Investigation of the Lead-Lag Relations of Returns and Volatilities among the KOSPI200 Spot, Futures and Options Markets and their Explanations. Journal of Emerging Market Finance. n. 5. 2006.

KAWALLER, I. G.; KOCH, P. D.; KOCH, T. W. The Temporal Price Relationship Between S\&P 500 Futures and the S\&P 500 Index. The Journal of Finance. v. 42, n. 5. 1987.

KOFMAN, P.; MARTENS, M. Interaction between Stock Markets: an Analysis of the Common Trading Hours at the London and New York Stock Exchange. Journal of International Money and Finance. v. 16, n. 3. 1997.

LAMEIRA, V. J.; NESS JR, W. L.; SOARES, T. D.; Governança Corporativa: Impactos no Valor das Companhias Abertas Brasileiras. Revista de Administração da Universidade de São Paulo, v. 42, p. 64-73, 2007.

LIMA, M. E. Dupla Negociação e Arbitragem entre Ações e ADRs de Empresas Brasileiras: Uma Análise Empírica. Brasília: UnB, 2005.

MACEDO, N. D.; Iniciação à Pesquisa Bibliográfica: guia do estudante para a fundamentação do trabalho de pesquisa. $2^{\mathrm{a}}$ Ed. São Paulo: Loyola, 1994. 
MANTEGNA, R. N.; STANLEY, H. E. An Introduction to Econophysics - Correlations and Complexity in Finance. Cambridge University Press. Cambridge. 2000.

MATSUMOTO, A. S.; BORGES, R. O. Integração e Possibilidades de Arbitragem entre o Mercado Brasileiro de Ações e o Mercado de ADR no Período de 2001 a 2003. Anais do $4^{\circ}$ Congresso USP de Controladoria e Contabilidade. 2004.

MATTAR, F. N. Pesquisa de Marketing. 4. ed. São Paulo: Atlas, 1996.

MUSSA, A.; YANG, E.; TROVÃO, R.; FAMÁ, R. Hipótese de Mercados Eficientes e Finanças Comportamentais: As Discussões Persistem. FACEF Pesquisa. São Paulo, v. 11, n.1, p. $5-17,2008$.

NYSE - Disponível em <www.nyse.com>. Acesso em 15 de Setembro de 2009.

OLIVEIRA, G. R. Testando a Existência de Efeito Lead-Lag entre os Mercados Acionários Norte-Americano e Brasileiro. 2008. Dissertação de Mestrado. FACE/PPGA - Universidade de Brasília.

RIBEIRO DA SILVA, A. C. Metodologia da Pesquisa Aplicada à Contabilidade: Orientações de estudos, projetos, artigos, relatórios, monografias, dissertações e teses. São Paulo: Atlas, 2003.

ROSA, R. S. ADR e a Sua Influência na Cotação da Empresa no Brasil. 2004. Trabalho de Conclusão de Curso de Graduação em Ciências Econômicas. Universidade Federal de Santa Catarina.

ROSS, S. A.; WESTERFIELD, R. W.; JAFFE, J. F. Administração Financeira Corporate Finance. $2^{\mathrm{a}}$ Ed. São Paulo: Atlas, 2008.

VERGARA, S. C. Projetos e Relatórios e Pesquisa em Administração. 2. ed. São Paulo: Atlas, 2000.

WORLD FEDERATION OF EXCHANGES - Disponível em < <ttp://www.worldexchanges.org/statistics/ytd-monthly>. Acesso em 23 de Setembro de 2009. 